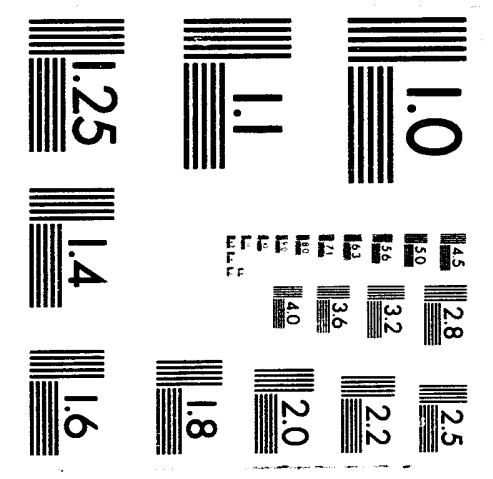




\title{
AN INTEGRATED ASSESSMENT OF ELECTRIC POWER RESOURCE OPTIONS IN THE U.S. VIRGIN ISLANDS
}

\author{
Lawrence J. Hill \\ Oak Ridge National Laboratory \\ Robert A. Chronowski \\ Alternative Energy Development, Inc. \\ Andrew M. Shapiro \\ Verment Energy' Investment Corp.
}

Date Published: February 1994

\section{Prepared for}

U.S. VIRGIN ISLANDS ENERGY OFFICE

(Through Sandia National Laboratories)

\author{
OAK RIDGE NATIONAL LABORATORY \\ Oak Ridge, Tennessee 37831 \\ Managed by \\ MARTIN MARIETTA ENERGY SYSTEMS, INC. \\ for the \\ U.S. DEPARTMENT OF ENERGY \\ under Contract No. DE-AC05-84OR21400
}




\section{CONTENTS}

LIST OF FIGURES $\ldots \ldots \ldots \ldots \ldots \ldots \ldots \ldots \ldots \ldots \ldots \ldots \ldots$

LIST OF TABLES $\ldots \ldots \ldots \ldots \ldots \ldots \ldots \ldots \ldots \ldots \ldots \ldots \ldots \ldots$

PREFACE $\ldots \ldots \ldots \ldots \ldots \ldots \ldots \ldots \ldots \ldots \ldots \ldots \ldots \ldots \ldots \ldots \ldots \ldots \ldots \ldots$

ABSTRACT $\ldots \ldots \ldots \ldots \ldots \ldots \ldots \ldots \ldots \ldots \ldots \ldots \ldots \ldots \ldots \ldots \ldots \ldots$

EXECUTIVE SUMMARY $\ldots \ldots \ldots \ldots \ldots \ldots \ldots \ldots \ldots \ldots \ldots \ldots$

1. INTRODUCTION $\ldots \ldots \ldots \ldots \ldots \ldots \ldots \ldots \ldots \ldots \ldots \ldots \ldots \ldots \ldots \ldots$

1.1. Purpose of the Study $\ldots \ldots \ldots \ldots \ldots \ldots \ldots \ldots \ldots \ldots \ldots$

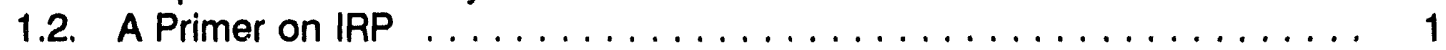

1.2.1. What is IRP? . . . . . . . . . . . . . . . 1

1.2.2. Contribution of DSM Programs .............. 3

1.2.3. IRP and the Regulatory Environment ........... 5

1.2.4. Impact of the Energy Policy Act of 1992 (EPACT) . . . . . . . 7

1.3. Conduct of the Assessment $\ldots \ldots \ldots \ldots \ldots \ldots \ldots \ldots \ldots$

1.4. Remainder of the Report $\ldots \ldots \ldots \ldots \ldots \ldots \ldots \ldots \ldots$

2. ELECTRICITY IN THE USVI: AN OVERVIEW $\ldots \ldots \ldots \ldots \ldots \ldots \ldots \ldots \ldots \ldots$

2.1. Relevant Institutions .......................... 11

2.2. Joint Production of Water and Power $\ldots \ldots \ldots \ldots \ldots \ldots \ldots$

2.3. Electricity Consumption Patterns ................. 13

3. THE SUPPLY SIDE $\ldots \ldots \ldots \ldots \ldots \ldots \ldots \ldots \ldots \ldots \ldots \ldots$

3.1. Existing and Committed Generating Units $\ldots \ldots \ldots \ldots \ldots \ldots$

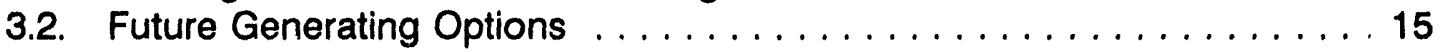

3.2.1. Combustion Turbines . . . . . . . . . . . . . . . 15

3.2.2. Wind Energy . . . . . . . . . . . . . . . . . 18

3.2.3. Purchased Power . . . . . . . . . . . . . . . . 18

3.3. Other Renewable Possibilities $\ldots \ldots \ldots \ldots \ldots \ldots \ldots \ldots \ldots \ldots$

3.3.1. Power From Waste . . . . . . . . . . . . . . . . . . . 18

3.3.2. Ocean Thermal Energy Conversion (OTEC) . . . . . . . . . . . 19

3.3.3. Other Renewable Supply Options . . . . . . . . . . . . . . . . . . 19

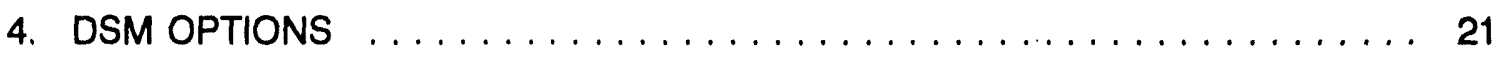

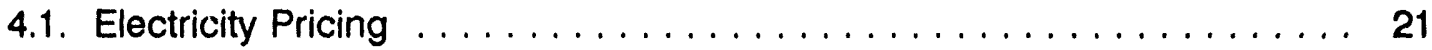

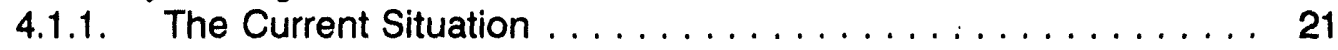

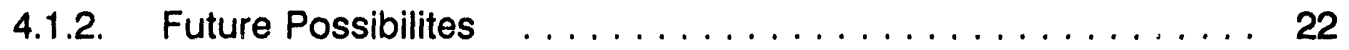

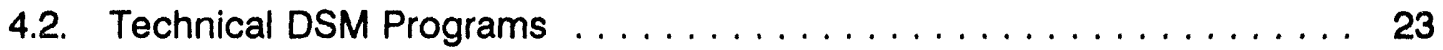

4.2.1. Residential Programs .................... 24

4.2.2. Commercial and Industrial Programs . . . . . . . . . 28

4.2.3. New Construction Program . . . . . . . . . . . . . . . 32 


\section{CONTENTS (CONT.)}

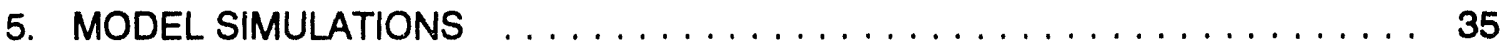

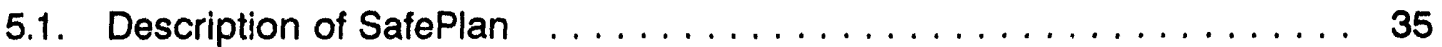

5.2. Five Scenarios ... . . . . . . . . . . . . . . . . . . . . . . 37

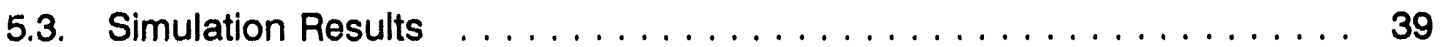

5.3.1. Five Scenarios . . . . . . . . . . . . . . . . 39

5.3.2. Wind Generation as a Resource Option . . . . . . . . . . . 44

6. RECOMMENDATIONS $\ldots \ldots \ldots \ldots \ldots \ldots \ldots \ldots \ldots \ldots \ldots \ldots \ldots$

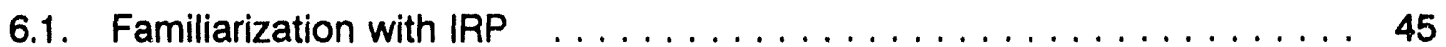

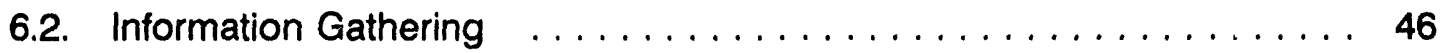

6.3. Resource Integration $\ldots \ldots \ldots \ldots \ldots \ldots \ldots \ldots \ldots \ldots \ldots$

REFERENCES $\ldots \ldots \ldots \ldots \ldots \ldots \ldots \ldots \ldots \ldots \ldots \ldots \ldots \ldots$

APPENDIX A: TECHNICAL DSM PROGRAMS $\ldots \ldots \ldots \ldots \ldots \ldots \ldots \ldots$

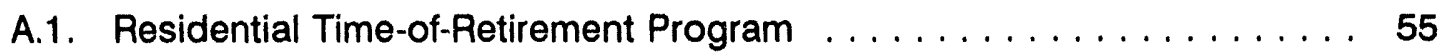

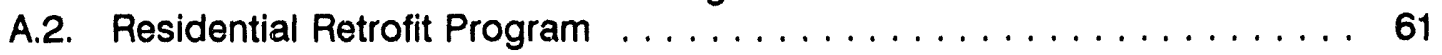

A.3. Commercial/Industrial Time-of-Retirement Program . . . . . . . . . 65

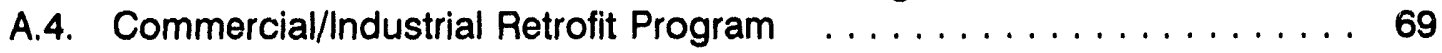

A.5. Commercial/Industrial Load Management Program . . . . . . . . . . 75

A.6. New Construction Program . . . . . . . . . . . . . . . . 79 


\section{UST OF FIGURES}

\begin{tabular}{ccccc}
\hline Figure & Description & Page \\
\hline 1 & Integrated Resource Planning as Part of a Dynamic Process & $\ldots$ & 2 \\
2 & Characterization of Incremental and Total Resources $\ldots \ldots$ & $\ldots \ldots$ & 5 \\
3 & DSM Contributions to Resource Additions, Utility Survey & $\ldots$ & $\ldots$ & 6 \\
4 & Calculation of Cost-Benefit Ratios in SafePlan & $\ldots \ldots$ & $\ldots$ & $\ldots$ \\
\hline
\end{tabular}

$\varepsilon$ 


\section{LIST OF TABLES}

\section{Table}

Description

Page

S.1 Summary of Effects of Implementing DSM Programs, Five

Scenarios, USVI Water and Power Authority

U.S. Electric Utilities, Estimated Energy and Peak Load Savings

from DSM Programs

2 Electricity Consumption, Customers, and Average Usage, USVI

Water and Power Authority, 1987 and 1992

Key Variables for Existing and Committed Generating Capacity, USVI Water and Power Authority

Key Variables for Residential DSM Programs, U.S. Virgin Islands

Key Variables for Commercial and Industrial Programs, U.S. Virgin

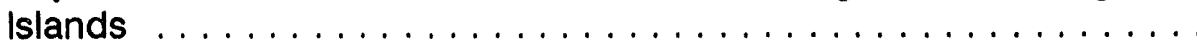

6

Key Variables for New Construction Programs, U.S. Virgin Islands

iDefinition of Scenarios for Model Simulations, St. Thomas and St. Croix

8 Cost-Benefit Ratios for DSM Programs from Model Simulations . . . 40

9 Cost Savings from Running DSM Programs, St. Thomas and

St. Croix

Energy and Capacity Contributions of DSM Programs, St.

Thomas and St. Croix, 2002 and 2012 


\section{PREFACE}

The funds for completing this study for the U.S. Virgin Islands Energy Office (VIEO) were made available from the U.S. Department of Energy (DOE), Grant DE-FG-4488R-410584. However, any opinions, findings, conclusions, or recommendations expressed herein are those of the authors and do not necessarily reflect the views of either the VIEO or DOE.

In addition, because this report has several audiences, it is written at several levels. For readers familiar with the U.S. Virgin Islands and its electric power sector, the background information on electricity in the islands may seem superficial. For readers sophisticated in such issues as demand-side management, integrated resource planning, and differences hetween financial and economic analyses, the background discussion of these issues may be tedious. There are always trade-offs in presenting different materials for diverse audiences. We hope that the proper balance was struck.

Finally, this assessment could not have been undertaken and completed without the cooperation and assistance of many people at the U.S. Virgin Islarids Water and Power Authority (WAPA) and the Virgin Islands Energy Office (VIEO). Although there are too many to acknowledge individually, we would be remiss in not mentioning key people. At WAPA, Alberto Bruno-Vega, the Executive Director, and Donald Francois, the Chief Operating Officer, facilitated the collection of information by making themselves and their staff available throughout the study. Special thanks go to Glenn Rothgeb and George Shepherd who coordinated visits to the generating sites on St. Thomas and St. Croix, respectively. At VIEO, Director Claudette Young-Hinds's enthusiasm and interest in energy conservation and integrated resource planning set the over-all tone for the assessment. Onaje Jackson, Coordinator of the VIEO's Renewable Energy Center, and the project manager for the assessment, provided guidance and assistance throughout the course of the study. Finally, we thank Onaje, Beth Richards of Sandia National Laboratories, Skip Laitner of Economic Research Associates, and Eric Hirst of Oak Ridge National Laboratory for providing comments on draft versions of the report. 


\section{ABSTRACT}

As with other island-based, insular power systems, the avoided cost of power for the Water and Power Authority (WAPA) of the U.S. Virgin Islands (USVI) is high relative to that of U.S. mainland electric utilities. First, the need to produce potable water requires that WAPA's electric generating system operate at efficiency levels lower than would result in the absence of the need to jointly produce water and power. Second, the inability to purchase power from neighboring utilities necessitates higher reserve margins than would be required if WAPA had sources from which to purchase power.

These two operating conditions suggest that integrated resource planning (IRP) should be especially attractive to WAPA. IRP is a planning paradigm that gives electric utilities more options to choose from when making resource selections and, therefore, generally results in lower costs. That is, rather than choosing from among conventional generating alternatives to satisfy future load requirements, utilities also look to the demand side as a source of resources--i.e., demand side management (DSM)--in this planning process. They then select the least-cost mix of resource options.

In this study, we take the first steps toward implementing an IRP process in the USVI. Using its existing resource base and the supply and DSM options that it has in the future, we simulated WAPA's resource selection process over a 20 -year planning horizon using SafePlan, an IRP planning model. The results suggest that WAPA can significantly reduce its cost of providing electricity by implementing DSM programs. For example, under external conditions most favorable for generating electricity with fossil fuels--i.e., no increase in the real price of fuel input costs over the 20-year period--the cost of generating electricity and the amount of $\mathrm{kWh}$ needed over that period can be reduced nearly nine percent by implementing cost-effective DSM programs. Cost and kWh savings are greater under less favorable assumptions about (1) the input costs for generating electricity and (2) other conditions that WAPA will confront in the future. The results also indicate that DSM programs targeted at the residential sector can save 500 gallons of water annually for participants in the program.

These dollar and energy savings are only indicative of the potential. Although they include savings for the types of DSM programs that have proved cost-effective for mainland utilities (e.g., load management and commercial and industrial lighting programs), data limitations prevented development of other DSM programs that have also proved cost-effective on the mainland--especially for industrial customers. Therefore, a major recommendation of the study is that this data gap be closed. One way to accomplish this is to survey WAPA's customers to find out the penetration levels of appliances and characterize the consumption behavior of WAPA's customers. Information gained in the survey can supplement data obtained from running pilot DSM programs. The renewable energy district in Frederiksted created by the USVI Energy Office is a good place to conduct pilot studies because of the wealth of information already collected on its electricity customers. 


\section{EXECUTIVE SUMMARY}

In this study, we show that, by implementing cost-effective demand-side management (DSM) programs, the Water and Power Authority (WAPA) of the U.S. Virgin Islands (USVI) can meet its future energy service needs at costs lower than constructing and/or operating electric generating units. The DSM activities include (1) setting cost-based prices and (2) implementing programs to improve the efficiency of electricity-using durables used by WAPA's customers. The dollar and kWh savings from implementing DSM programs under various assumed conditions are summarized in Table S.1.

\section{Table S.1}

Surnmary of Effects of Implementing DSM Programs

Five Scenarios

USVI Water and Power Authority

(In Percentages)

Scenario

Savings Resulting from DSM

Cost $^{\mathrm{a}} \quad$ Energy

No Fuel Price Increases ${ }^{c}$

8.9

8.5

EIA Fuel Price Forecasts ${ }^{d}$

8.8

8.9

High Fucl Price Increases ${ }^{\theta}$

10.0

8.9

High Peak Load Growth'

13.1

10.0

Environmental Externalities ${ }^{g}$

9.0

8.7

SOURCE: Section 5 in text.

${ }^{a}$ The cost savings (i.e., net present value) in 1992 constant dollars over the next 20 years resulting from implementation of cost-effective DSM programs. See Table 10 in text for additional detail.

'The percentage of kWh provided by cost-effective DSM programs in the year 2002. See Table 11 in text for more detail.

${ }^{\mathrm{C}}$ Assumes that real fuel prices do not increase over the forecast period.

${ }^{d}$ Assumes that fuel prices increase at the rates projected by the Energy Information Administration (EIA).

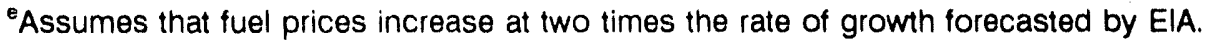

'Assumes that peak load grows at one percentage point higher than that projected by WAPA.

Inclucies a cost for environmental externalities, effactively increasing the cost of producing electricity using fossil fuel generating units. 
The results in Table S.1 suggest that the conclusions are robust, prevailing over a wide range of conditions that WAPA could conceivably confront over the next 20 years. As Footnote a indicates, cost savings are the percentage reduction in costs over a 20year planning horizon from implementing cost-effective DSM programs. Cost-effective DSM programs are those for which the estimated costs of implementation are less than their estimated benefits (see Table 9 in text for cost:benefit ratios for DSM programs under the five scenarios). Likewise, as Footnote $b$ indicates, the energy savings are the amount of kWh saved as a result of implementing DSM programs (see Table 11 in text).

The results in Table S.1 were obtained by applying the principles of integrated resource planning (IRP) to WAPA's electric power delivery system. IRP is a management tool that allows utilities to consistently compare the cost-effectiveness of all their resource options--those on both the demand and supply side--taking into account the financial, economic ar,d reliability differences of those resources. Simply put, the IRP process increases the choices available to an electric utility in meeting its load growth. The utility then selects the mix of options with the lowest cost. U.S. utilities have found that they can cost-effectively lower capacity requirements by more than 25 percent using the IRP process. This occurs while simultaneously meeting all customer service needs, and generally with lower costs per kWh.

All DSM options included in the simulations were compared to a 22-MW combustion turbine generating unit, WAPA's avoided unit. Because of data limitations, it was not possible to quantify the parameters for every potentially cost-effective DSM measure. Based on experiences elsewhere, it is expected that some of the most prominent savings lie in measures whose parameters cannot be quantified without further study. Therefore, the dollar and kWh savings shown in Table S.1 understate the costeffective potential for DSM programs. The six DSM programs and corresponding measures that were included in the simulations (with results in Table S.1) are:

- residential time-of-retirement program

- solar water heating

- cooling

- residential retrofit program

- lighting

- other, including such measures as low-flow faucets and showerheads, increased insulation, and the like

- commercial and industrial time-of-retirement program

- cooling

- commercial and industrial retrofit program

- lighting

- new construction

- residential

- load management program 
- commercial

Measures that were not part of the simulations (and, therefore, their savings are not included in Table S.1), but which should prove cost-effective after quantifying the parameters of the program include:

- cost-based electricity pricing

- residential time-of-retirement program

- refrigeration

- commercial and industrial time-of-retirement program

- solar water heating

- motors

- other, including refrigerators, stoves, ovens, and the like

- commercial and industrial retrofit program

- other, based on custom energy audits

- new construction

- commercial

- load management program

- industrial

Other conclusions emerging from the assessment include:

- Because of declining operating costs experienced over time in applications elsewhere, electricity generated from wind could be competitive in the USVI in the medium term if land can be made available at a reasonable price. Government-provided land can be used for other high-value purposes--i.e., it has a high opportunity cost.

- An offer from the Amerada-Hess Corporation to supply up to $15 \mathrm{MW}$ of capacity on an interruptible basis on St. Croix has financial merit from WAPA's standpoint. However, from an economic point of view, DSM activities are more attractive because of the environmental externalities associated with the Hess power.

- W'aste management is a pressing need in the USVI, but the energy potential from a waste to power operation is not sufficient for WAPA to expend its scarce resources. However, the plant(s) may be attractive to the private sector.

- The ocean thermal energy conversion (OTEC) proposition should only be considered if WAPA bears no risk beyond agreeing to buy the electricity and water at its avoided cost.

- The combination of small land mass, geological features, and relatively small total demand limits the cost-effectiveness of other central-station, supply-side renewable energy options on WAPA's system. As a result, options such as mini-hydro, solar 
thermal, and geothermal were not considered in this study. Their cost-effectiveness in the USVI awaits further technological development and/or experience elsewhere. However, there are many decentralized and demand-side applications of solar photovoltaics on the Islands.

- On the water side, the production facilities have a satisfactory performance record. Leaky distribution systems are the fundamental cause of water-supply problems to end users. Although an effort to remedy this is underway, there can be no real relief until funds are made available to repair these distribution systems.

The primary recommendation of this study is that this initial IRP assessment be converted into an IRP process at WAPA. That is, as Table S.1 suggests, changing conditions external to WAPA (e.g., changing fuel input prices, higher electricity demand growth rates) can change the cost-effectiveness of different resource options. This suggests that IRP is not a one-time assessment, but rather a continuing process. Recognizing the dynamics of this process, it is important that IRP be institutionalized at WAPA. One approach used by mainland utilities is to use a team concept with representatives from all departments of WAPA. The center of the process, an integration team, takes input from demand-side and supply-side teams. The integration team is ultimately responsible for developing the integrated plan and making resource acquisition recommendations to upper management.

Also, data collection on electricity customers is a first-order priority in institutionalizing the IRP process. One approach is to conduct surveys of WAPA's residential, commercial, and industrial customers on St. Thomas and St. Croix, supplementing the energy audit data being collected in the Frederiksted renewable energy district. Another complementary approach is to conduct pilot programs of potentially the most cost-effective DSM programs such as load management and commercial and industrial lighting programs. A good place to conduct the pilot programs is in the renewable energy districts created by the Virgin Islands Energy Office. Data collected from these pilots can be used to develop island-wide DSM programs.

Finally, to implement the IRP process in the USVI, we recommend that appropriate parties familiarize themselves with its phases and components. For commissioners of the USVI's PSC, the WAPA governing board, and upper-level WAPA management, we recommend an executive familiarization session, lasting three or four hours. For staff of 'WAPA and the VIEO, we recommend lengthier sessions, running for three to five days and using this report as the reference point for the sessions. Any additional training can be provided by general DSM and IRP workshops conducted on the mainland. 


\section{INTRODUCTION}

\subsection{PURPOSE OF THE STUDY}

The U.S. Virgin Islands (USVI) has a number of electric power resource options available to it on the demand side to meet future load growth in addition to constructing and operating combustion turbine generating plants. The purpose of this study is to determine the most cost-effective mix of those demand and supply options over the next 20 years. To accomplish this, the principles of integrated resource planning (IRP) were applied to the electric power clelivery system of the USVI's Water and Power Authority (WAPA), the sole public utility in the islands. The assessment was coordinated by Oak Ridge National Laboratory for the USVI Energy Office (VIEO) and WAPA.

\subsection{A PRIMER ON IRP}

\subsubsection{What is IRP?}

Spurred by the rising costs of constructing new electric generating plants, high fuel costs, and increasing environmental concerns over emissions from fossil fuel plants, electricity producers in many countries are looking to the demand side as a source of resources for meeting energy (i.e., kWh) and load (i.e., kW) requirements. That is, changing the pattern and level of electricity demand (i.e., demand-side management (DSM)) is weighed as a resource option on an equal footing with traditional supply resources (e.g., building new generating stations, extending the life of old ones, or purchasing power from other sources). The process of selecting a resource mix on the basis of comparing the benefits and costs of demand and supply resources is referred to as integrated resource planning (IRP). The IRP process is a combination of (1) traditional least-cost planning, a process by which utilities minimized the cost of generating a given amount of electricity and (2) demand-side planning. Its goal is to provide needed electricity at the lowest possible economic, social, and environmental cost.

In Figure 1, we place DSM planning in the context of a dynamic electric utility planning framework, including (1) factors that motivate utilities to consider DSM planning, (2) the relationship between demand-side planning and the IRP process, and (3) the implementation and evaluation of both DSM and supply resources (Hill, Hirst, and Schweitzer, 1991). The process is dynamic not only because planning by its very nature is evolutionary but also, as we show in Figure 1, because the effectiveness of DSM programs has feedback effects on both the process of selecting the programs and the way in which they are implemented. The effectiveness of DSM programs, of course, can be determined only by systematic program evaluation (Hill, Hirst, and Schweitzer, 1992a).

As we show in Figure 1, the regulatory environment (discussed further in Section 1.2.3) and characteristics of a utility's power delivery system and customer demand influence decisions on whether to pursue IRP. For example, the types of generating units used by electric utilities can be a motivating force to consider the demand side. Based on statistical analysis of responses to a survey of 24 U.S. utilities, the percent of total peak $(\mathrm{kW})$ resources projected to be met by DSM is larger for utilities with greater 
Figure 1

Integrated Resource Planning as Part of a Dynamic Process

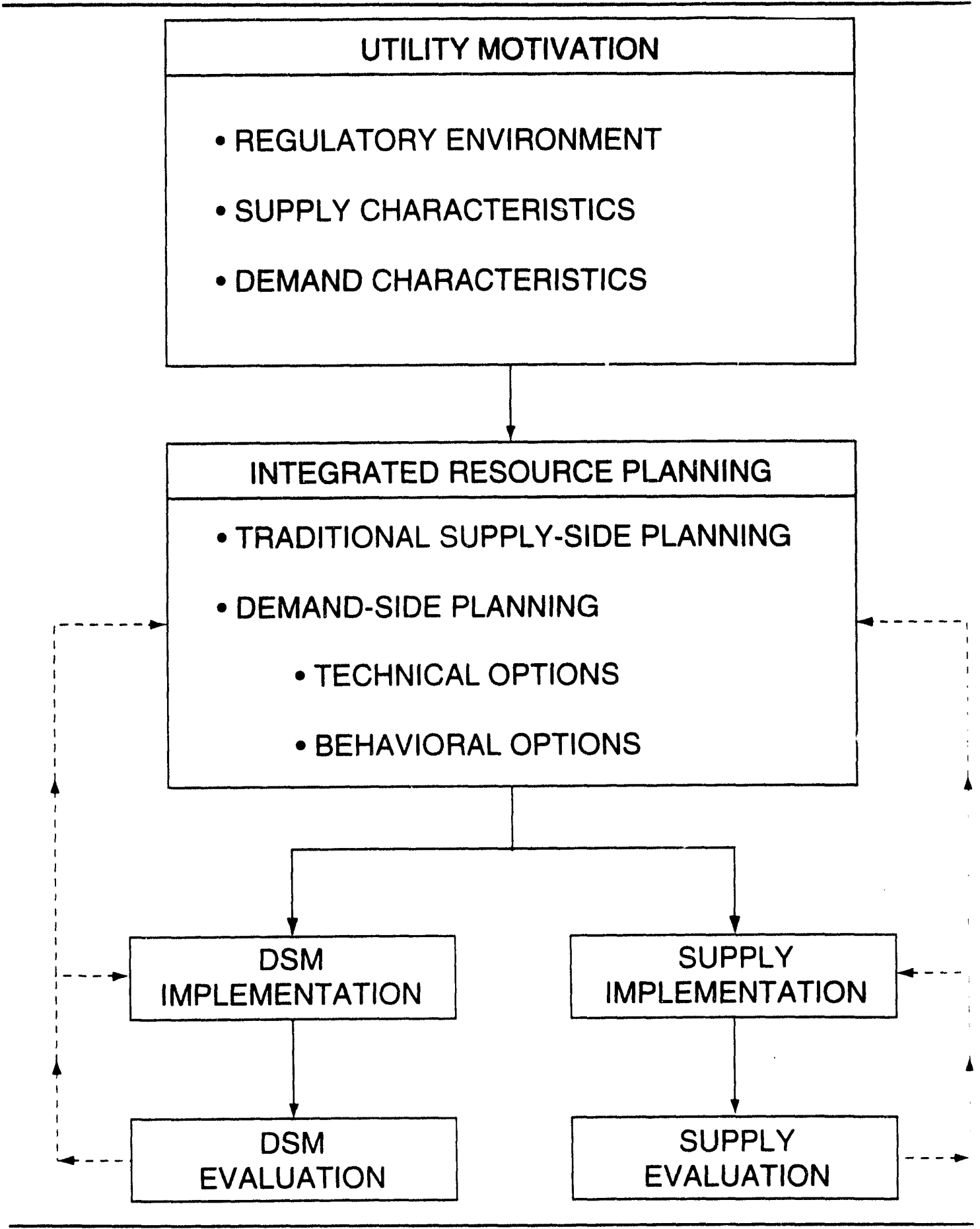


dependence on oil and gas generating units, which have higher costs per $\mathrm{kWh}$ generated. Similar conclusions result from energy consumption ( $k W h$ ) avoided by conservation programs. That is, if production costs are higher, utilities try harder to promote reductions in their customers'consumption (Schweitzer, Hirst, and Hill, 1991). On the demand side, utilities with low load factors are more likely to seek ways to shave peak load. There are several powerful DSM tools that can be used to accomplish this, including electricity pricing (Hill, 1990, 1991a). The goal in all cases is to find the mix of supply and demand resources that lowers cost and, therefore, increases potential profits.

The final two sets of blocks on implementation and evaluation are important. DSM programs are implemented and evaluated in the same way that supply resources are. That is, DSM programs are treated parallel to the manner in which a utility chooses to (1) build a power plant, (2) construct it, and (3) evaluate its performance. The problem that many utilities confront in treating DSM and supply resources in a parallel manner is the lack of data on running DSM programs. The technical savings of the $\theta$ programs are generally well known. It is the marketing side where utilities are deficienl because firms do not have enough information to know how their decisions will affect their potential profits. They need information on:

- the number of customers using different types of electricity-using durables and, therefore, the total amount of savings available from a program;

- the possible market penetration of energy-efficient durables;

- quantification of the trade-offs between marketing these durables and their penetration, and

- the most effective financing mechanisms for different programs.

\subsubsection{Contribution of DSM Programs}

In Table 1, we present some evidence on the contribution of DSM programs to meeting future electric energy $(\mathrm{kWh})$ and peak load $(\mathrm{kW})$ in the United States. The results are based on survey responses from 24 U.S. electric utilities (Schweitzer, Hirst, and Hill, 1991). The 24 utilities represent one-third of the U.S. electric utility industry in terms of peak load. The survey results are presented on two bases: (1) the percentage of total resources (i.e., energy services supplied) accounted for by running DSM programs, which can also be interpreted as the percentage reduction of total demand attributable to running DSM programs and (2) the percentage of incremental resources (i.e., energy services supplied) accounted for by running DSM programs, which is the fraction of additional resources added by utilities in the 10-year period from 1990 to 2000 that are accounted for by DSM programs.

To facilitate understanding these two bases, we characterize them in Figure 2 (Hill, Hirst, and Schweitzer, 1991). The No Incremental DSM curve is a reference forecast from the Current Year forward, a best-guess of what load is going to be before including the estimated effects of DSM options. The Projected Load curve is a forecast of future load requirements, including the effects of DSM programs. Existing Supply Resources refers 


\section{Table 1}

U.S. Electric Utilities

Estimated Energy and Peak Load Savings from DSM Programs (In Percentages)

\begin{tabular}{lccccc}
\hline Type of Savings & \multicolumn{2}{c}{ Energy $^{\mathrm{a}}$} & & \multicolumn{2}{c}{ Peak Load $^{\mathrm{a}}$} \\
\cline { 3 - 5 } & 1990 & 2000 & 1990 & 2000 \\
\hline Total Resource Basis & 0.5 & 3.8 & 1.3 & 6.2 \\
Incremental Resource Basis & NA & 15.5 & NA & 27.7 \\
\hline
\end{tabular}

SOURCE: Schweitzer, Hirst, and Hill, 1991.

aWeighted average, based on responses from 24 utilities. Peak could occur in the summer or winter depending on the demand characteristics of individual utilities.

NA - Not Available

to the amount of generating capacity that is committed and known at the time the plan is being developed. That amount is shown declining over the forecast horizon in Figure 2 , implying a net depreciation of supply resources.

The survey results shown in Table 1 indicate that U.S. utilities will significantly increase their DSM activities on a total resource basis from 1990 to 2000 . In the year 2000 , peak demand, for example, is forecasted by these 24 utilities to be 6.2 percent less than it otherwise would be if DSM programs were not implemented. The savings on an incremental basis are much larger, of course. Nearly 30 percent of additional peak electric power resources $(\mathrm{kW})$ will come from the demand side in 2000 . Projected energy savings ( $\mathrm{kWh}$ ) are one-half of projected peak load savings, suggesting that load management programs (e.g., direct load control programs that change the time when electricity is used) are more pervasive and/or effective than those aimed at improving energy efficiency (e.g., conservation programs). This will likely increase from state initiatives and from recent passage of the Energy Policy Act of 1992 (as discussed in Section 1.2.4 of this report).

The data in Table 1 are weighted averages of the 24 utilities responding to the survey. Clearly, different utilities with different operating conditions will have different potentials for DSM savings. For example, all other conditions the same, utilities that aggressively pursued DSM programs in the past will not have the same savings potential ten years from now as those utilities just beginning DSM planning. Utilities with different climates and different load factors will also have different DSM potentials. To demonstrate 
Figure 2

Characterization of Incremental and Total Resources

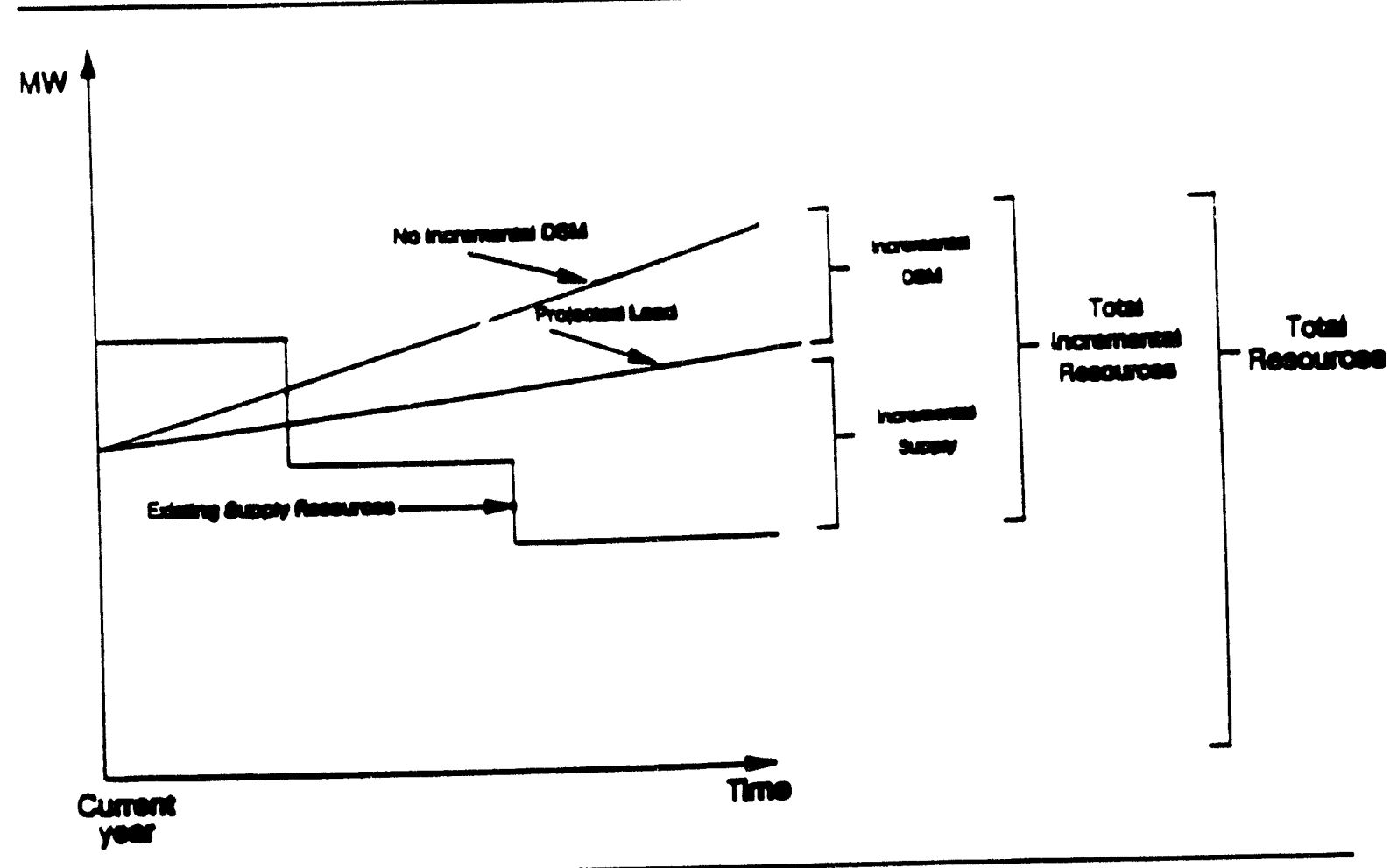

different potentials across utilities, we disaggregate the survey results presented in Table 1 to individual utilities in Figure 3 for the incremental resource projections. Some of the utilities are projected to get as much as one-half of their additional energy and peak load resources from DSM resources in the the next ten years. Other utilities, however, will not obtain as much as five percent of their energy requirements from DSM programs. The variation across utilities is large.

\subsubsection{IRP and the Regulatory Environment}

An important feature of the resource planning environment is the relationship between a utility and its state regulatory commission. The nature of this relationship varies substantially from state to state due to a variety of factors, including the history of relations between utilities and their regulators, regional regulatory and political culture, and the nature of legal requirements imposed by legislation or administrative order.

Studies focusing on various aspects of this relationship (e.g., Mitchell and Wellinghoff, 1989; Chamberlin, Fry, and Braithwait, 1988) concluded that, while virtually all states encourage resource planning, many do not require that the plan be approved by the state. In some cases, a long-range plan must be submitted for regulatory 
Figure 3

DSM Contributions to Resource Additions

Utility Survey

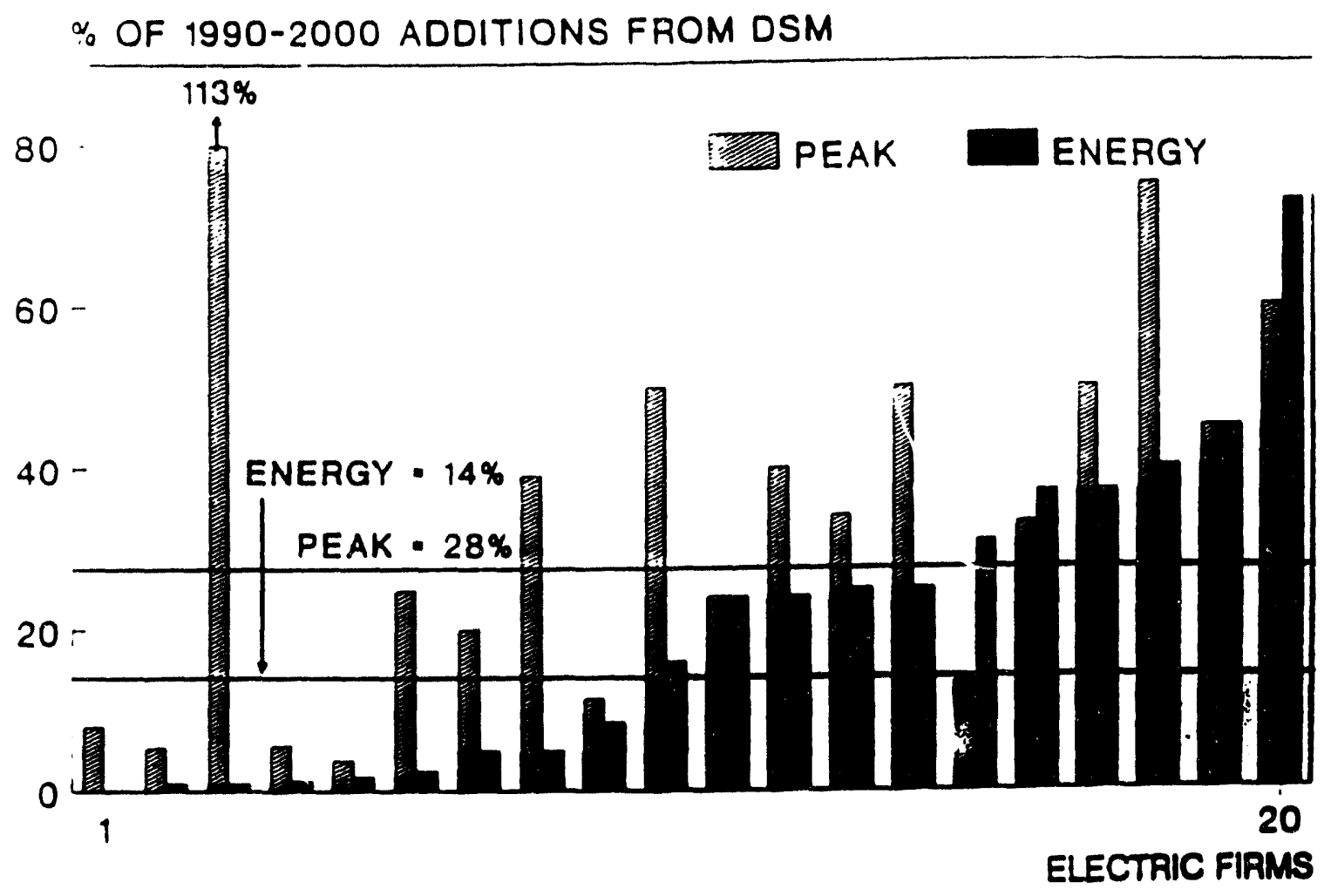

approval, but the contents of the plan are not prescribed. In others, formal approval is not required; but the plans must address certain issues, such as treatment of uncertainty. A number of states have recently passed regulations requiring that DSM resources be treated equally (or even preferentially) with supply resources. Other states are in the process of passing similar regulations.

Of the 24 states included a survey of utilities (Schweitzer, Hirst, and Hill, 1991), legislation or administrative order in 18 require utilities to prepare integrated resource plans. And, eleven of the commissions in the 18 states formally approve the plans. Finally, approval by the commission for use of a resource depends on its inclusion in a formal resource plan in seven of the states. Statistical analyses of the responses of these utilities in these 24 states suggest that utilities required by legislation or administrative order to prepare long-term integrated resource plans rely more heavily on DSM to meet additional peak demand than those utilities not required to prepare a plan . 
Filing requirements vary widely. In Nevada, for example, utilities are required to file an Electric Resource Plan with the Public Service Commission every three years, extending 20 years into the future. Utilities in North Carolina, on the other hand, must file a comprehensive description documenting the planning process every three years; an update is required in the intervening two years.

A recent survey of all PUCs (Cohen et al., 1990) shows the extent to which state regulatory authorities require externalities to be considered in utilities' selection of resources.' States were placed in one of four categories, depending on the degree to which externalities were required to be considered in selecting resources: (1) operational: approaches developed or rules passed; (2) developing approaches: not as yet implemented or failed to pass; (3) awareness of the problem, but no formal procedures established; or (4) no evidence of treatment of externalities. Combining the latter two categories into one, the results showed the following:

- 17 states had operational approaches;

- 7 states were developing approaches; and

- 24 states had not addressed the problem.

Therefore, more than one-third of the states had rules for treating externalities. The study showed that three approaches are used to take account of externalities:

- qualitative treatment in which externalities are assessed by relative degrees of environmental degradation;

- a percentage adder approach that either increases the cost of supply-side resources or decreases the cost of ones on the demand side; and

- quantification of the cost of externalities.

Eight of the 17 states that have rules for treating externalities require quantification of the environmental effects of using different resources. Also, several regulatory commissions indirectly incorporate externalities in the ratemaking process by permitting higher rates of return for resources which do not affect the environment. For example, Connecticut allows up to an additional five percent rate of return for investment in DSM programs.

\subsubsection{Impact of the Energy Policy Act of 1992 (EPACT)}

EPACT is a wide-ranging piece of energy legislation that has implications for how energy is produced and used for many years to come. Although many provisions of EPACT do not directly pertain to the USVI, certain provisions will have a significant impact: (i) energy efficiency--including those relating to electric utilities, (ii) changes to the Public Utility Holding Company Act, (iii) renewable energy, (iv) provisions for grants, taxes, and subsidies, and ( $v$ ) policies directed at insular areas. The purpose here is not to go into detail on how each of these provisions will affect the USVI. That already has been

\footnotetext{
${ }^{1}$ Tennessee and Nebraska, which are dominated by publicly owned utilities, were excluded from the survey.
} 
accomplished (Laitner and Holmes, 1993). Rather, here we provide pieces of EPACT relating to IRP, energy efficiency, and electric utilities.

EPACT amends the Public Utility Regulatory Policies Act of 1978 to include the following suggestion for PUCs to consider:

Each electric utility shall employ integrated resource planning. All plans or filings beiore a State regulatory authority to meet the requirements of this paragraph must be updated on a regular basis, must provide the opportunity for public participation and comment, and contain a requirement that the plan be implemented.

The profitability of investments on the demand side was also addressed by EPACT, again as a suggestion to PURPA's language:

The rates allowed to be charged by a State regulated electric utility shall be such that the utility's investment in and expenditures for energy conservation, energy efficiency resources, and other demand side management measures are at least as profitable, giving appropriate consideration to income lost from reduced sales due to investments in and expenditures for conservation and efficiency, as its investments in and expenditures for the construction of new generation, transmission, and distribution equipment. Such energy conservation, energy efficiency resources and other demand side management measures shall be appropriately monitored and evaluated.

\subsection{CONDUCT OF THE ASSESSMENT}

An assessment team, organized and coordinated by Oak Ridge National Laboratory, conducted the study in three phases. In the first phase beginning in January 1992, the team concentrated on the power delivery system. It involved discussions with WAPA staff members and on-site visits to WAPA's generating sites on both St. Croix and St. Thomas. The purpose of the discussions and site visits was to gain a better understanding of WAPA's power generating operations and to gather data on units presently in operation and those committed for the future.

The goals in this first phase were (1) to gain an understanding of the operations, maintenance, dispatch, and new capacity planning strategy and practices used by WAPA and (2) to review about 18 months worth of operations data (12 for St. Croix) to look at efficiencies and availabilities achieved, etc. The 12- and 18-month periods were selected as the best post-Hugo periods after the chaos of the huricane, and with the coming of normal operations. Pre-Hugo operations were not considered rclevant for the current IRP activity. The least-cost expansion plans were reviewed; the plants were given a walkthrough inspection; operation and maintenance data files were examined and selected information copied; O\&M staff were interviewed, and supervisory and management staff were interviewed. Finally, the activities were coordinated with staff of the VIEO. 
The purpose of the second phase was to gather information on demand-side options. The first-order priority was to gather data to quantify the parameters of such measures as improvements in residential and commercial lighting efficiency, residential solar water heaters, and load management programs. Data sources included information gathered from the renewable energy district on St. Croix and WAPA's customer billing data.

The information gathered in the first two phases was combined in the final phase. Resource options were ranked on the basis of cost:benefit ratios using SAFEPLAN, a flexible utility planning model designed to simulate resource selection.

\subsection{REMAINDER OF THE REPORT}

The remainder of the report has five sections. In the next section, we discuss the energy and water situation in general terms. After discussing the relevant institutions, we turn to the physical water and power supply systems and historical consumption patterns. In Sections 3 and 4, we discuss WAPA's existing and future supply and demand options, respectively. In Section 5, we discuss the simulation of resource selection, including the modeling tool, the scenarios, and the results. Our recommendations are presented in the final section. 


\section{ELECTRICITY IN THE USVI: AN OVERVIEW}

\subsection{RELEVANT INSTITUTIONS}

The U.S. Virgin Islands Water and Power Authority (WAPA) is a publicly owned, regulated utility responsible for the generation, transmission, and distribution (in reality generation and distribution) of electricity on the 3 main islands of the U.S. Virgin Islands chain, plus the production and distribution of water through large-scale distillation systems integrated with the major power plants on St. Thomas and St. Croix. Prior to 1988, WAPA produced and sold water to the water distribution system which was also owned by the government, but organized separately from WAPA. On January 1, 1988, the water distribution system was transferred to WAPA's control. The two systems are separately financed. The water system is a customer of the electric system, paying for both electricity and other shared administrative expenses of their joint operation. The tariffs of the water and electric power systems are regulated by the Public Service Commission in the islands.

Similar to mainland energy offices, the U.S. Virgin Islands Energy OHfice (VIEO) is an agency of the territory's government. For the past three years, it has offered a rebate program to WAPA's electricity customers for purchases of energy-efficient appliances, including solar water heaters, air conditioners, and refrigerators.

\subsection{JOINT PRODUCTION OF WATER AND POWER}

The St. Thomas and St. Croix electric systems are isolated from each other and the power systems of neighboring islands. Therefore, each has no fall-back position other than its own reserve capacity. St. John relies on an underwater cable connection from St. Thomas. It has a diesel generator that can handle about one-half of the island's peak demand.

The isolation of these systems is an important consideration in their daily operation because the power system dispatch strategy must take into account the vulnerability of the system to both routine and catastrophic failure. There is a severe economic penalty to be paid for power outages. WAPA does not have the advantage of inter-connection with other grids as either a shock absorber, or as sources for power purchases should it become necessary. Therefore, in comparison with other electric utilities, WAPA must maintain a larger generating capacity reserve margin to prevent against a catastrophic failure of the system.

The other important characteristic of the generating system is the production of distilled water from sea wator that is normally accomplished with turbo-generator extraction steam in a true cogeneration fashion. That is, the electric and water systems share dual-purpose plants for the production of electricity and water. Boilers used to supply steam for the operation of water desalination units also provide steam for turbines used in generating electricity. The steam demand of the evaporation systems is flat (i.e., a constant demand in pounds per hour of steam), which does not allow for the turbogenerators to be operated in a load following mode. 
Water production has a satisfactory record, but plagued by poor distribution facilities. The desalination systems perform admirably, but new capacity is not the best technical choice at this time. The distribution system is old and leaks badly. Between a marginal amount of water storage and the underground losses, the supply is almost always strained. The existing I.D.E. desalination systems are state-of-the-art systems. Experience over the years has proven that the integrated operations of water and electricity production equipment involves some loss of flexibility of dispatch on the electricity generation side.

Both the St. Thomas and St. Croix plants have a similar operations strategy based on similar equipment availability. Operations are tied directly to the production of water in such a way as to limit the operational efficiency of the power generation activities for about 12 hours per day. The insular nature of the electricity grids on both islands also dictates a certain conservative operational approach--and unit size selection for new capacity additions.

WAPA's operational strategy must be considered in the context of the current and projected future 24-hour demand curves. The curves differ between St. Thomas and St. Croix a iittle, mainly because of the heavier commercial, tourist-oriented mid-day air conditioning load on St. Thomas. This load extends the mid-day peak virtually flat for up to 5 hours, followed a little later by another shorter peak when the work force gets home. In terms of the ratio between the daily peak and daily minimum, there is similarity with a ratio of less than 2 to 1 for both systems. This is attributable to the night-time air conditioning load. St. Thomas should have a new gas turbine on-line shortly (sitting onsite with installation scheduled to imminently begin), which will give it a reasonably safe reserve capacity margin, plus the makings of a combined cycle installation with a waste heat boiler addition. St. Croix, on the other hand, has a tight reserve margin, a pressing need to do a major overhaul on 2 combustion turbines, a growing demand, and a wait of perhaps 12 to 18 months for the Southshore installation of $2 \times 24 \mathrm{~mW}$ Frame 5 combustion turbines to come on-line.

Looking at plant availability for the two sites explains the dispatch strategy. The steam units are efficiently operated throughout the day as baseload units. The extraction steam is productively used for the first stage driving heat for the multi-stage distillation process for seawater. The combustion turbines are operated for peaking at reasonably efficient load conditions during the day, and at night for outage protection at rather inefficient load conditions. These gas turbines are of the type that have very steep reductions in efficiency as the load is reduced. Therefore, there is a penalty in terms of fuel cost/kWh of production. The simple cycle gas turbines are operating at a heat rate on average a third above full load expectations. This strategy is appropriate under the current load conditions, and with current equipment.

The additional cost can be approximately quantified using simple assumptions. Of the total generation for the last 18 months, the combustion turbines produced about one quarter. Of their dispatch, about one-fitth of the hours are under poor load conditions. The load during these hours would is approximately 55 percent of the average, or a total of $15.6 \mathrm{MW}$. The extra fuel cost $/ \mathrm{kWh}$ is about a fifth above the average cost $(.2 \times .07)$ equals $\$ 0.014$ per $\mathrm{kWH}$. Therefore, the annual cost penalty for maintaining 
system flexibility for unforeseen problems is $15,600 \mathrm{~kW} X 2000$ hours per year $X \$ 0.014$ equals $\$ 436,800$ per year. That translates to an additional cost of about 1 cents per $\mathrm{kWH}$ produced, if spread out over the annual production. This is not an unreasonable burden to purchase operating security. Even if the cost is really double the estimate (upper extreme considering probability), it is still reasonable with what is currently available for WAPA.

As the demand grows, and newer more efficient dispatch choices become available, (more efficient combustion turbines and an ability to operate in combined cycle mode), this penalty should be reduced. The basic problem is that at least one extra unit must be kept on-line all night at a fairly low load so that it can rapidly pick-up load with any other fallure because of the desalination process requirement.

\subsection{ELECTRICITY CONSUMPTION PATTERNS}

In Table 2, we provide information on WAPA's electric power consumption, divided between St. Thomas (including St. John) and St. Croix. The two sets of data define WAPA's two separate power systems. WAPA's customers have increased by more than two percent per year on average over the past five years. For both islands, the majority of the increase on a percentage basis is attributable to the commercial sector. The growth in electric power consumption is somewhat deceiving because it includes data for 1990 , the fiscal year in which Hurricane Hugo hit the islands. Electricity demand growth on St. Thomas is much greater than that on St. Croix, explained in part by the effect of Hurricane Hugo on St. Croix. 
Table 2

Electric Consumption, Customers, and Average Usage

USVI Water and Power Authority

1987 and 1992

\begin{tabular}{|c|c|c|c|c|}
\hline & \multicolumn{2}{|c|}{ St. Thomas } & \multicolumn{2}{|c|}{ St. Croix } \\
\hline & $1987^{\mathrm{a}}$ & $1992^{\mathrm{a}}$ & $1987^{a}$ & $1992^{\mathrm{a}}$ \\
\hline \multicolumn{5}{|c|}{ Electricity Consumption (MWh) } \\
\hline $\begin{array}{l}\text { Residential } \\
\text { Commercial } \\
\text { Industrial }\end{array}$ & $\begin{array}{r}94,005 \\
52,664 \\
108,747\end{array}$ & $\begin{array}{r}112,008 \\
67,082 \\
144,130\end{array}$ & $\begin{array}{l}73,810 \\
28,195 \\
71,080\end{array}$ & $\begin{array}{l}81,032 \\
34,695 \\
64,589\end{array}$ \\
\hline Total $^{b}$ & 258,353 & 328,296 & 178,029 & 180,311 \\
\hline \multicolumn{5}{|c|}{ Number of Customers: } \\
\hline $\begin{array}{l}\text { Residential } \\
\text { Commercial } \\
\text { Industrial }\end{array}$ & $\begin{array}{r}18,121 \\
3,065 \\
358 \\
\end{array}$ & $\begin{array}{r}19,522 \\
3,890 \\
442 \\
\end{array}$ & $\begin{array}{r}16,380 \\
2,454 \\
345 \\
\end{array}$ & $\begin{array}{r}18,307 \\
3,203 \\
357 \\
\end{array}$ \\
\hline Total & 21,544 & 23,854 & 19,179 & 21,867 \\
\hline \multicolumn{5}{|c|}{ Average Annual Usage $(k W h):$} \\
\hline $\begin{array}{l}\text { Residential } \\
\text { Commercial } \\
\text { Industrial }\end{array}$ & $\begin{array}{r}5,227 \\
17,777 \\
297,123\end{array}$ & $\begin{array}{r}5,789 \\
17,522 \\
337,541\end{array}$ & $\begin{array}{r}4,541 \\
11,834 \\
207,230\end{array}$ & $\begin{array}{r}5,090 \\
12,986 \\
212,991\end{array}$ \\
\hline
\end{tabular}

SOURCE: USVI Water and Power Authority.

as of June 30, the end of WAPA's fiscal year.

Includes amounts for street lighting. 


\section{THE SUPPLY SIDE}

\subsection{EXISTING AND COMMITTED GENERATING UNITS}

In Table 3, we summarize characteristics of WAPA's existing electric generating units and those for which commitments have been made. The information is divided between the St. Thomas and St. Croix systems, reflecting the two insular power systems in the USVI. As the data indicate, we provide some background information on existing and committed units and the recent operating experience of the units, including average load, average heat rate, and fuel cost per unit generation. The 6-month difference in operating experience data between St. Thomas and St. Croix reflect the relative severity of problems on St. Croix since Hurricane Hugo.

The capacity and other operating variables at each plant have not been summed to a total for each of the islands. This is deliberate because of the integrated operations of the No. 6 oil steam turbine plants and the steam-consuming seawater distillation plants. When the distillation plants are operated, the extracted steam is taken at the expense of available electric generation capacity. The water production steam demand is nearly constant and the availability of the desalination systems is nearly 94 percent. Therefore, there is a built-in capacity restriction for the electricity plants. Also, because the steam demand for water production is virtually flat, there is another limiting factor--the system's capability to follow electricity demand changes without upsetting the stability of water production. A summing of capacity amounts, therefore, is without foundation.

As the data in Table 3 indicate, St. Thomas should have a new gas turbine on-line shortly, which will provide a reasonably safe reserve margin, plus the prospect of a combined cycle installation with a waste heat boiler addition. St. Croix, on the other hand, has a tight reserve margin, a pressing need to perform a major overhaul on 2 combustion turbines, growing demand, and a delay of 12 to 18 months for the Southshore installation of $2 \times 24 \mathrm{MW}$, Frame 5 combustion turbines to come on-line.

The daily operation of both systems was described in detail in Section 2.2 above.

\subsection{FUTURE GENERATING OPTIONS}

\subsubsection{Combustion Turbines}

A 22-MW combustion turbine is used as the avoided generating unit in this study. That is, the capacity benefits of employing any resource--whether that resource is another type of generating unit (discussed below) or a DSM program--is based on the capacity cost of a 22-MW combustion turbine. The combustion turbine costs $\$ 400 / \mathrm{kW}$ and uses No.2 fuel. The cost of the fuel is scenario-based and will be discussed at length in Section 5. The fixed O\&M cost is $\$ 16 / \mathrm{kW} /$ year. The total cost of the combustion turbine, therefore, is assumed to be $\$ 8.8$ million and its construction period is assumed to be three years with 20 percent completed in the first two years and 60 percent completed in the year prior to its coming on line. 
Table 3 Key Variables for Existing and Committed Generating Capacity
USV Water and Power Authority

\begin{tabular}{|c|c|c|c|c|c|c|c|}
\hline \multirow[b]{2}{*}{$\begin{array}{l}\text { Unit Type } \\
\text { (Number) }\end{array}$} & \multicolumn{4}{|c|}{ Background Information } & \multicolumn{3}{|c|}{ Recent Experience } \\
\hline & $\begin{array}{l}\text { Fuel } \\
\text { Type }^{b}\end{array}$ & $\begin{array}{l}\text { Rated (Actual) } \\
\text { Capacity (MW) }\end{array}$ & $\begin{array}{l}\text { Heat Rate } \\
\text { (Btus/kWh) }^{c}\end{array}$ & $\begin{array}{l}\text { First } \\
\text { Year }\end{array}$ & $\begin{array}{l}\text { Average } \\
\text { Load (MW) }\end{array}$ & $\begin{array}{c}\text { Avg. Heat } \\
\text { Rate (Btus/kWh) }\end{array}$ & $\begin{array}{l}\text { Fuel Cost/ } \\
\text { kWh (c/kWh) }\end{array}$ \\
\hline \multicolumn{8}{|l|}{ St. Thomas/St. John } \\
\hline $\begin{array}{l}\text { Steam Turbine \#11 } \\
\text { Combustion Turbine \#12 } \\
\text { Steam Turbine \#13 } \\
\text { Combustion Turbine \#14 } \\
\text { Combustion Turbine \#15 } \\
\text { Diesel \#7J } \\
\text { Combustion Turbine \#18 }\end{array}$ & $\begin{array}{l}\text { No. } 6 \\
\text { No. } 2 \\
\text { No. } 6 \\
\text { No. } 2 \\
\text { No. } 2 \\
\text { No. } 2 \\
\text { No. } 2\end{array}$ & $\begin{array}{rr}18.8 & (16.0) \\
15.1 & (14.0) \\
36.9 & (36.0) \\
15.1 & (14.0) \\
24.1 & (21.2) \\
2.5 & (2.5) \\
24.1 & (22.0)\end{array}$ & $\begin{array}{l}14,226 \\
15,500 \\
13,179 \\
15,000 \\
13,659 \\
11,375 \\
12,500\end{array}$ & $\begin{array}{r}1968 \\
1970 \\
1973 \\
1972 \\
1981 \\
1985 \\
\text { NA }\end{array}$ & $\begin{array}{r}13.3 \\
7.6 \\
23.6 \\
8.6 \\
12.1 \\
2.0 \\
\text { NA }\end{array}$ & $\begin{array}{l}15,874^{\circ} \\
20,778 \\
13,967^{\circ} \\
19,894 \\
17,972 \\
12,276 \\
\text { NA }\end{array}$ & $\begin{array}{l}5.6 \\
7.4 \\
4.8 \\
7.1 \\
6.4 \\
5.6 \\
\text { NA }\end{array}$ \\
\hline \multicolumn{8}{|l|}{ St. Croix } \\
\hline $\begin{array}{l}\text { Steam Turbine \#10 } \\
\text { Steam Turbine \#11 } \\
\text { Combustion Turbine \#16 } \\
\text { Combustion Turbine \#17 } \\
\text { Diesel } \\
\text { Combustion Turbine } \\
\text { Combustion Turbine }\end{array}$ & $\begin{array}{l}\text { No. } 6 \\
\text { No. } 6 \\
\text { No. } 2 \\
\text { No. } 2 \\
\text { No. } 2 \\
\text { No. } 2 \\
\text { No. } 2\end{array}$ & $\begin{array}{rr}7.5 & (7.5) \\
19.2 & (16.0) \\
24.1 & (20.0) \\
24.8 & (21.2) \\
4.2 & (2.5) \\
24.1 & (22.0) \\
24.1 & (22.0)\end{array}$ & $\begin{array}{l}12,000 \\
12,000 \\
13,659 \\
12,450 \\
11,850 \\
11,850\end{array}$ & $\begin{array}{r}1967 \\
1970 \\
1981 \\
1988 \\
1968 \\
\text { NA } \\
\text { NA }\end{array}$ & $\begin{array}{r}5.2 \\
13.2 \\
10.2 \\
11.6\end{array}$ & $\begin{array}{l}15,160^{\circ} \\
12,949^{\circ} \\
22,564^{\dagger} \\
18,367^{\prime}\end{array}$ & $\begin{array}{l}6.4 \\
4.9 \\
8.0 \\
6.5\end{array}$ \\
\hline
\end{tabular}

SOURCE: Water and Power Authority. 


\section{Table 3 (Cont)}

${ }^{a}$ For St. Thomas, recent experience is defined to be an 18-month period from the middle of 1990 until the end of 1991 . For St. Croix, recent experience is the calendar year 1991.

'Type of petroleum.

The heat rate is an estimated achievable value at $100 \%$ rated load based on HHV, and for steam plants with no extraction steam used.

'The year that the unit was first operated.

-Adjusted for productive cogeneration extraction.

Waste heat boiler performance is not considered.

NA - Not applicable. 


\subsubsection{Wind Energy}

Until the actual wind resource at specific Virgin Island locations can be defined, it is possible to use some other Caribbean Island experience plus U.S. cost standards to give the wind option a tangible feel. Land availability and cost are the main determinants after the resource is defined. The important facts about wind are that reliability is increasing while the capital and O\&M costs have been steadily dropping. Wind is a legitimate utility supply option with acceptable reliability, and competitive kWH production cost if both the resource and land are available. In Section 5, we define the operating characteristics of a $250 \mathrm{~kW}$ wind plant.

\subsubsection{Purchased Power}

A short-term contract with Hess to provide some reserve margin during the next 12 to 18 months on St. Croix should be considered. Assuming energy sales of $180 \mathrm{MWh}$ for St. Croix in 1992 and the interconnection with Hess costs $\$ 1.25$ million, the burden on WAPA customers would be about 0.5 cents per kWH for this security. If the power can be purchased for a lower price than it costs WAPA to produce peak power, then it should be dispatched regularly for peaks to compensate for the costs born for the hook-up, and not be used exclusively as a back-up reserve. For example, if Hess uses a mix of commercial and non-commercial fuels (refinery gas), the fuel cost should be below that of WAPA's. Assuming that Hess pays less for No.2 fuel than what WAPA pays for distillate, the estimated incremental fuel cost per kWH for Hess" can be calculated. With a better heat rate (higher efficiency) than WAPA can achieve because of a better demand profile, Hess should profit and the transaction can be cost-effective for WAPA. Estimating Hess' No. 2 fuel cost to be $\$ 0.40$ per gallon, and at a heat rate of 10,666 BTU per kWH, the fuel cost increment is approximately $\$ 0.03 / \mathrm{kWh}$. With other incremental cost elements also lower for Hess than for WAPA, this would give Hess and WAPA the proper amount of negotiating room to arrive at a favorable price for Hess and a savings for WAPA. This could substantially reduce the potential 0.5 cents per $\mathrm{kWH}$ customer burden by simply connecting to the Hess capacity.

\subsection{OTHER RENEWABLE POSSIBILITIES}

\subsubsection{Power from Waste}

Both St. Thomas and St. Croix have municipal garbage problems that are related to space shortages and the environment. The volume of garbage is not large (below 200250 tons per day per island), and the energy potential is only 1.0 to $2.0 \mathrm{MW}$ per island. The possibility of transferring garbage from one island to the other is interesting, but not feasible for aesthetic reasons. The waste problem is real, but it is an environmental problem. From a policy standpoint, options should be pursued, but WAPA should not have its resource base diluted by responsibility for a complicated problem that has only a limited energy benefit.

One alternative worth considering is the potential of locating the waste to energy plants at or adjacent to the existing WAPA plants (extremely sensitive and politically volatile consideration), and using the steam source to displace the need for total reliance 
on the existing conventional steam plants to drive the desalination units for potable water production. The steam could be produced by, and purchased from a private entity, along with any power produced, or power could be swapped for water from the waste-fired sceam plant. Options such as these need to be reviewed in detail. Their viability needs to be verified in the public arena, and a development strategy prepared, if viability is indicated.

\subsubsection{Ocean The, r.a! Energy Conversion (OTEC)}

Some private U.S. energy companies have been soliciting WAPA for participation in an OTEC project off the shore of St. Croix where an excellent OTEC potential exists. Because no commercially operating OTEC plants exist in the world, WAPA is not in a position to take any position that involves risk in such a project. It can, however, structure an agreement that would encourage a private sector developer in assuming the development risk. For example, WAPA could offer a take or pay contract that only binds it to guarantee payment for $\mathrm{kWh}$ delivered, if the construction is started by a certain date, and the plant is commissioned by a certain date.

Perhaps of greater importance to WAPA is the potential for an OTEC plant to produce distilled seawater. While this aspect of the technology needs to be carefully evaluated further because of the possibility of extremely low temperatures (the temperatures would dictate a very severe vacuum condition at some expenditure of energy to allow the flashing to take place). If the distillation proves feasible, then the value of dual production of electricity and water could overcome an OTEC plants high capital cost. A reasonable cost range for the first commercial, 5-MW OTEC plant producing 2 million gallons per day of seawater is $\$ 40$ million to $\$ 50$ million. With a power sales price of $\$ 0.10$ per $\mathrm{kWH}$, and a water sales price of $\$ 10 / 1000$ gallons, the private sector might be tempted to take the risk for a long-term take or pay sales contract.

\subsubsection{Other Renewable Supply Options}

The limited extent of the land masses, the nature of the terrain, and the relatively smiall electricity demand all serve to limit the options for other renewable energy sources. For example, there are no potential water sources wilh sufficient volume, consistency, and head to consider hydro as an option. The grid is essentially everywhere, and with land issues, this inhibits the options for solar photovoltaics, except for specialized applications. Total electricity demand is too low to consider solar thermal, especially within the constraints of the desalination plants. There are no evident geothermal resources. 


\section{DSM OPTIONS}

In this section, we define demand-side possibilities for WAPA's two delivery systems. We organize the discussion around two topics: (1) behavioral possibilities (i.e., a tariff structure reflecting cost-based rates) and (2) technical ones (i.e., programs to improve the technical efficiency of electricity use by WAPA's customers).

\subsection{ELECTRICITY PRICING}

\subsubsection{The Current Situation}

The USVI's Public Service Commission (PSC) approves all changes in electricity rates proposed by WAPA. In this process, the overall level of electricity rates is set to ensure that WAPA generates a 1.25 interest coverage ratio. Defined as the ratio of earnings to debt service costs, the coverage ratio is an indication of WAPA's ability to service its fixed interest charges. It is part of the covenant between WAPA and its debtholders.

Partially to ensure that WAPA achieves this coverage level, in August 1981 the PSC approved a levelized energy adjustment clause (LEAC) for the rate structure. The LEAC establishes the level of fuel costs to be recovered by WAPA for six-month periods. It is based on projections of those costs and is adjusted for any prior period's over or under recovery of actual fuel costs. From July through December 1991, the LEAC rate was $\$ .016152$ per $\mathrm{kWh}$.

In addition to LEAC, in April 1991 the PSC allowed WAPA to petition for a temporary increase in the LEAC rate in excess of fuel costs to satisty any deficiency in funds necessary to acquire the St. Thomas waste heat recovery boiler. The increase was limited to a maximum two mills per kWh of electricity sales.

Finally, a Maintenance and Capital Fund Surcharge was allowed by the PSC in August 1982 to compensate WAPA for increases in the cost of producing electricity. In April, 1991, the PSC ordered the Maintenance and Capital Fund Surcharge to be a part of WAPA's base rates. The surcharge is currently $\$ 0.016897$ per kWh of electricity sales.

WAPA's current electricity rate structure was implemented in July, 1979 by PSC Order No. 23-1979. The order established five classes of electric service: residential, commercial, large power (demand-metered), street lighting, and private security lighting service.

Residential users pay a fixed, customer charge of $\$ 2.73$ or $\$ 7.45$ per month, depending on the type of service. The variable charge is $\$ 0.09$ per $\mathrm{kWh}$ for consumption less than $200 \mathrm{kWh}$ and $\$ 0.0741$ per $\mathrm{kWh}$ for consumption exceeding $200 \mathrm{kWh}$ per month. Similarly, all commercial customers pay a monthly fixed charge: $\$ 2.68$ for single phase and $\$ 9.71$ for three phase service. The $\mathrm{kWh}$ charge for the amount of electricity consumption also varies: $11.59 \% / \mathrm{kWh}$ up to $1,000 \mathrm{kWh}$ per month, and $9.74 \mathrm{c} / \mathrm{kWh}$ thereafter. 
Charges for large power users depend on the amount of contracted capacity. That is, although the demand charge of $\$ 1.62$ per month is the same irrespective of the amount of contracted capacity, the variable charge is a function of the amount of contracted capacity.

Currently, the 'average' residential customer on St. Thomas--consuming 393 $\mathrm{kWh} /$ month and using a single-phase system-paid $\$ 48.02$ for electric service (l.e., $\$ 2.68+200 * \$ 0.09+193 * \$ 0.0741)$. On, St. Croix, the average residential customer with 297 $\mathrm{kWh}$ per month pays $\$ 34.50$. Because the 'average' customer on St. Thomas uses more electricity than the average on St. Croix, the average price paid by the typical St. Thomas customer is higher. Similarly, the 'average' commercial customer on St. Thomas consuming $1,321 \mathrm{kWh}$ per month and using a single-phase system--paid $\$ 193.50$ per month for electric service. On St. Croix, the corresponding amount is $\$ 124.67$. Again, because of higher usage by the average customer, the average price per customer is lower for St. Thomas' commercial customers.

\subsubsection{Future Possibilities}

WAPA's residential, commercial, and industrial tarifts are block rates, consisting of a fixed customer charge and declining energy charges--i.e., declining block rates. That is, the more consumption that a customer has in succeeding rate 'blocks,' the lower the average rate paid. Or, alternatively, the marginal price charged for succeeding blocks of electricity consumption declines as more electricity is used.

Declining block rates are addressed by the Public Utility Regulatory Policies Act of 1978:

The energy component of a rate, or the amount attributable to the energy component in a rate, charged by any electric utility for providing electric service during any period to any class of electric consumers may not decrease as kilowatt-hour consumption by such class increases during such period except to the extent that such utility demonstrates that the costs which are attributable to such energy component decrease as such consumption increases during such period.

There is ample room for WAPA to use electricity pricing as a JSM strategy by devising cost-based electricity rates. The costs of serving different customer classes depends on the pattern of customer loads. Ideally, a tariff could be devised to capture the customer habits of each individual customer. In practice, of course, this is infeasible. An option to aggregate WAPA's customers into broad categories is the use of block rates, as WAPA has currently implemented. However, their current tail block rate structure was devised in 1979; consuming habits have changed dramatically since then.

In other jurisdictions, cost-based electricity pricing has proved a powerful tool to manage electricity demand. Using electricity pricing as a DSM strategy is a behavioral complement used by many Western utilities as part of their technical DSM strategies. It can be used both by itself and as a financial incentive for other demand-side measures (Hill, 1990, 1991a). 
To influence the pattern of electricity demand, the most widely adopted pricing strategy by Western utilities other than block rates is time-of-use (TO) pricing, which refers generally to electricity rates which vary over the course of a year: hour-by-hour, day-by-day, or season-by-season (Hill, 1990). Time-of-day (TOD) pricing, a form of the general class of TOU rates, has generally been effective in shifting electricity consumption from peak to off-peak periods. And, at least for higher volume users (highvolume residential and higher-voltage commercial and industrial users), it has proven to be cost-effective in the United States. Western utilities have also used another form of a TOU tariff, an interruptible or curtailable (I/C) one, to reduce demand on days when capacity utilization is approaching its limit, usually offering rate incentives to large-volume, high-voltage consumers in return for shedding load for a limited amount of time on short notice. From every indication, these tariffs have been successful in reducing both U.S. and Western European capacity requirements.

In the immediate future, time-of-day pricing does not seem to be cost-effective for the residential sector in the USVI. For it to be cost-effective, average consumption levels should be around $1200 \mathrm{kWh}$ per month, typically caused by the penetration of air conditioners and swimming pools (Hill, 1991c). With average consumption levels less than $500 \mathrm{kWh}$ in the USVI's residential sector, devising a residential TOD rate structure does not seem to be worthwhile.

Cost-based electricity pricing does seem to be cost-effective in the commercial and industrial sectors. However, to devise cost-based prices for these two customer classes, a cost-of-service study must be undertaken. The most recent cost-of-service study was completed in 1987 (Beck and Associates, 1987).'

\subsection{TECHNICAL DSM PROGRAMS}

We consider six technical DSM programs, cutting across different end uses and sectors of WAPA's customers:

- a residential time-of-retirement program, including solar water heating, cooling, and refrigeration measures.

- a residential retrofit program, including lighting and other, miscellaneous measures;

- a commercial and industrial time-of-retirement program, including water heating, cooling, electric motors, and other measures;

- a commercial and industrial retrofit program, including lighting and other measures;

- a commercial and industrial load management program; and

\footnotetext{
'Beck and Associates was completing an updated cost-of-seivice study at the time this report was being prepared.
} 
- a new construction program, including measures to improve the energy efficiency of new residential and commercial establishments.

In the next three sections, we discuss assumptions of the DSM programs for (1) residential customers, (2) commercial and industrial customers, and (3) new construction programs, respectively.

\subsubsection{Residential Programs}

In Table 4, we summarize characteristics of five residential DSM measures. The measures fall into one of two program categories: time-of-retirement (TOP) or retrofit programs. The TOR measures are targeted at customers when they replace their air conditioners, water heaters, and refrigerators. For the lighting measure of the retrofit program, bulbs and lighting fixtures are installed by WAPA directly because customers lack sufficient information on lighting technologies and their applications. The 'other' measure of the retrofit program is related to the lighting measure. It is implemented simultaneously with the lighting measure. As the note to Table indicates, starred entries (l.e., **') for the refrigeration measure in the TOR program indicate that sufficient data to quantify the parameters of this measure are nol available. The data in Table 4 are divided between those specific to St. Thomas (including St. John) and St. Croix and those common to both islands. Detail on common program data are in Appendices A.1 and A.2 for the TOR and retrofit programs, respectively.

Total customers for each of tha five measures are total residential customers as of June 1992, the end of WAPA's fiscal year. They are the same for each measure. The customer program base is the number of customers assumed to have the durable under consideration. For example, we assume that all residential customers have lighting fixtures and bulbs. However, we assume that only three-quarters of households have water heaters (footnote $\theta$ in Table 4), one-fifth have room air-conditioners (footnote f), and $90 \%$ have electric refrigerators (footnote g). Also, we only consider room air conditioners because of insufficient data on the penetration of central air conditioners in households.

For common program characteristics in Table 4, the dollar cost and energy savings per participant are based on specific features of each measure. They will be discussed in more detail below. Maximum participation rates and the number of years required to 'ramp up' to the maximum vary across measures. That is, given characteristics of customers such as income and education levels, a relationship exists between the (1) percentage of an electricity-uging durable's cost financed by the utility, (2) utility spending for promotion of the program, (3) maximum customer participation, and the (4) 'ramping' rate to maximum participation. For example, if WAPA were to finance more of the cost of an energy-efficient air conditioner, it is likely that more than 50 percent of the customers would purchase the efficient one after three years $-i$. $\theta .$, the maximum participation rate would be greater than 50 percent. For the measures listed in Table 4, we assume conservative ramping rates and maximum participation levels, loosely based on the experiences of other utilities running similar programs. The year-byyear participation for each of the measures is provided in Appendices A.1 and A.2.

The conservation load factor (CLF) for each of the measures in Table 4 defines 
Tablo 4

Koy Variables for Residential DSM Programs

U.S. Virgin latands

\begin{tabular}{|c|c|c|c|c|c|}
\hline \multirow{2}{*}{ Category } & \multicolumn{3}{|c|}{ Time-of-Retirement Program } & \multicolumn{2}{|c|}{ Retrofit Program' } \\
\hline & Water Heating & Cooling & Refrigeration & Lighting & Othere \\
\hline $\begin{array}{l}\text { SL Thomas/SL John } \\
\text { Total Customers } \\
\text { Customer Program Base }\end{array}$ & $\begin{array}{l}19,522 \\
14,642^{\circ}\end{array}$ & $\begin{array}{l}19,522 \\
3,904^{1}\end{array}$ & $\begin{array}{l}19,522 \\
17,570^{\circ}\end{array}$ & $\begin{array}{l}19,522 \\
19,522\end{array}$ & $\begin{array}{l}19,522 \\
19,522\end{array}$ \\
\hline $\begin{array}{l}\text { Se Croix } \\
\text { Total Customers } \\
\text { Customer Program Base }\end{array}$ & $\begin{array}{l}18,137 \\
13,603^{\circ}\end{array}$ & $\begin{array}{l}18,137 \\
3,627\end{array}$ & $\begin{array}{l}18,137 \\
16,323^{\circ}\end{array}$ & $\begin{array}{l}18,137 \\
18,137\end{array}$ & $\begin{array}{l}18,137 \\
18,137\end{array}$ \\
\hline $\begin{array}{l}\text { Common Program Charactistics } \\
\text { Cost per Participant } \\
\text { Savings per Participant (kwh) } \\
\text { Maximum Participation (\%) } \\
\text { Years to Attain Maximum } \\
\text { Conservation Load Factor } \\
\text { Cost of Conserved Energy (c/wm) }\end{array}$ & $\begin{array}{c}5900^{h} \\
1,698^{\prime} \\
75 \\
3 \\
60 \\
4.2\end{array}$ & $\begin{array}{c}\$ 64^{i} \\
400^{m} \\
50 \\
3 \\
40 \\
1.4\end{array}$ & 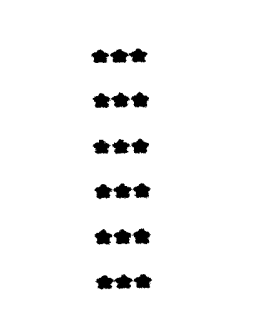 & $\begin{array}{c}5179 \\
304^{n} \\
60 \\
10 \\
40 \\
3.3\end{array}$ & $\begin{array}{c}540^{k} \\
233^{\circ} \\
60 \\
10 \\
50 \\
3.3\end{array}$ \\
\hline
\end{tabular}

An entry of "woens that reliable data are not currenty aveloble to quently the paramelers of this portion of the progran.

The DSM measures under time-ofretiremen programs are inplemented when a new reptacemert durable is purchased-e.e. at the tine the durable is copreciated.

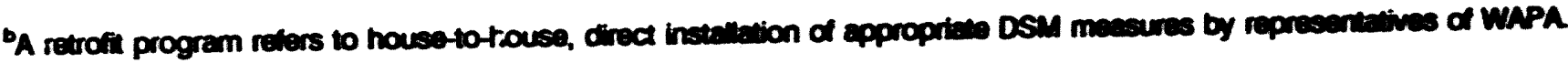

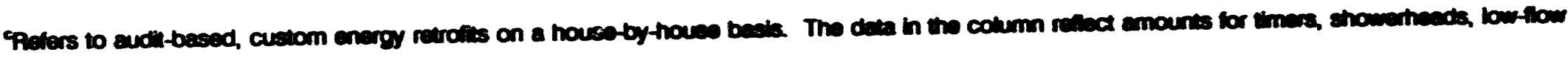




\section{Table 4 (Cont)}

feucetts, and water heater tank wraps for those not purchasing solar water hoesers.

"Customers as of June 30, 1992, the end of WAPA's fiscal yeer.

-Assumption: $75 \%$ of households have electric hat water heesers.

'Assumption: $20 \%$ of households have room air conditioners.

-Assumption: $90 \%$ of households have electric refrigeralors.

"Assumption: WAPA pays one-half the cost of a solar water heater (2850 average). Assuming a $15 \%$ administration cost, the utily's cost per unit is 5980

The incremental cost of the higher-efficiency unit is \$112. Assuming that WAPA pays one-hall of this amount with a 15\% administration fee, the average cost to WAPA is \$64 per customer.

'Assumption: One-third of the customers are high-usage lighting homes (F220 cost to WAPA) and wo-thirds are low-usage homes (F158). The S179/custor is a weighed average of the two The high-usace homes need on average 3.3 magnetic compact thurescents, 22 elactronic compact $\$ 179 /$ customer is a weighed average of the two. The high-usage homes need on average 3.3 magnetic compact thuorescents, 22 electronic compact

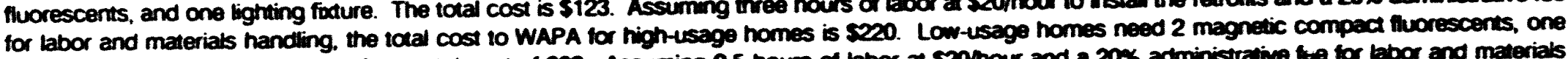
electronic, and one lighting foture for a total cost of 582 . Assuming 2.5 hours of labor at seomour and a $20 \%$ administrative lbe for bbor and materia's handing. the total cost to WAPA is $\$ 158$.

"Assumption: $20 /$ customer for shower heads, faucetts, and hot water heater wraps and a 520 installation lee.

'Assumption: One-third, two-thirds, weighted average savings of high-usage (3,000 kWm/year) and low-usage (1,200 kWh/ea) Cusiomers. High-usage customers save only 90 percent of lotal usage because they continue to use electricily as a backup to their system.

The average high-efficiency air-conditioner is assumed to seve $400 \mathrm{kum}$ per year.

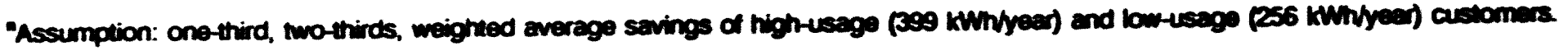

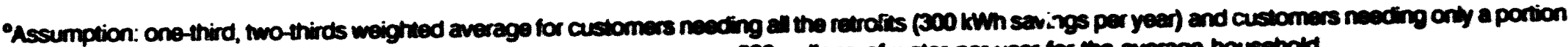
$200 \mathrm{kWh}$ per year of savings). Aso, the water saving measures seve 500 geilons of water per year for the average housechold

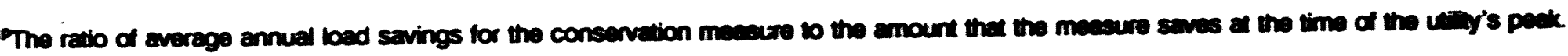


the relationship between the energy savings of a program (l.e., kWh) and the demand savings (l.e., $\mathrm{kW}$ ) at the time of WAPA's peak. The Cl.F is used primarily for modeling purposes, defining the amount and timing of a measure's savings. As the data in Table 4 indicate, the CLF varies for each measure. Finally, the cost of conserved energy (CCE) for each of the programs is listed in Table 4, indicating the relative attractiveness of the DSM measures. The CCE for each of the measures is calculated in Appendices A.1 and A.2 and shown for information purposes only. In comparing DSM measures with generating capacity alternatives in the modeling simulations (Section 5 below), the components of CCE are used: the annual costs of the measures and the total amount of energy saved annually relalive to respective amounts for generating alternatives.

The USVI appears to have the climate to support a cost-effective residential solar water heating program. These programs are cost-effective in regions with similar climates such as Jamaica (Conservation Law Foundation, 1990). WAPA could use a number of different financing and promotion mechanisms for this program. One would be to subsidize local solar water heater dealers to reduce the retail price of units so that they will be competitive with other types of water heaters. Another would be to finance the price difference between a solar water heater and other types with no financing charges for buyers. Another method would be to pay the total cost of installing solar water heaters. In this study, we assume that WAPA pays the difference between a solar heater and a conventional one.

We further assume that 14,642 households on St. Thomas and 13,603 on St. Croix have water heaters (Table 4). We further assume that a conventional water heater has an eight-year life. Therelore, the number of customers requiring solar water heaters each year is 1,830 on St. Thomas and 1,700 on St. Crolx. After running the program for three years, 75 percont of the customer base participate (Table 4). To attain this penetration rate, WAPA must pay one-half the additional cost of a solar heater in comparison with a conventional one. As footnote $h$ in Table 4 indicates, that amounts to $\$ 850$ per heater. Assuming 15 percent administration, WAPA must expend $\$ 980$ on each participant.

Given conditions in the USVI, a number of possibilities exist to improve the efficiency of room air conditioners used in households. One possibility would be to establish progressive pertormance standards for new room air conditioners that are sold and/or imported into the USVI. This results in a phase-in time for the air conditioners to reach the maximum technical potential of energy efficiency. However, based on a preliminary analysis, it seems that most air conditioners are imported from the U.S. mainland which already has energy efficiency standards.

Another mechanism for increasing the penetration of more efficient air conditioners would be to provide financial incentives to customers purchasing efficient models. Here, we assume that financial incentives are provided to customers at the time of retirement of their old air conditioners. As footnotes $i$ and $m$ to Table 4 indicate, we assume that one-half of residential customers purchase Japanese mini-split air conditioners and the other half purchases high-efficiency window units. Assuming that WAPA pays one-half of the incremental cost of these air conditioners over conventional ones, this results in an out-of-pocket expenditure of $\$ 388$ per participant by WAPA including 15 percent for administration (Table 4). We further assume that one-tenth of the air conditioners are 
replaced each year. This means that 390 and 363 aro replaced annually on St. Thomas and St. Croix, respectively. After three years, one-half of these customers are assumed to participate in the program--i.e., 50 percent maximum participation. The parameters of this measure are defined turther in Appendix A.1.

The amount of savings and cost-effectiveness of a DSM measure to increase refrigeration efficiency depends, of course, on the number, type, and energy-efficiency of refrigerators currently used in the USVI. As indicated in Table 4, data were not avallable to reasonably estimate the parameters of a refrigeration measure in the residential TOR program.

A DSM measure to increase the penetration of efficient household lighting in the USVI could achieve significant energy savings for WAPA while lowering energy costs for household customers. There are many different types of energy-efficient compact fluorescent bulb and ballast combinations that could be used in USVI households. Selection should be made on a house-by-house basis as part of a direct-installation, retrofit program to provide the required amount of lighting and to fit existing fixtures in USVI homes. An example would be to replace incandescent bulbs with ballasts that have screw-in adapters so that lighting fixtures would not have to be replaced. In cases in which screw-in replacements are not appropriate, fluorescent fixtures would be used as replacement lighting.

Although the initial cost of energy-efficient fluorescents is significantly higher than their incandescent counterparts, a fluorescent bulb will outlast 13 incandescents. Because of high up-front costs, however, this measure must be made attractive to customers when designing a DSM program. The most appealing option is to provide the energy-efficient lights and fixtures at no cost to customers. And, because it is difficult for the average customer to identify the appropriate lighting retrotits, the measure should be part of a direct-installation program. In this program, representatives of WAPA visit customers' homes and install the appropriate lighting retrofits in high-use locations. Because of limited data on lighting in the USVI, we use features of the Jamaican experience (Conservation Law Foundation, 1990) in developing the residential lighting measure in this study. As Footnotes j and $n$ to Table 4 indicate, we assume that twothirds of residences are small-usage and the other two-thirds are high-usage.

As part of the direct-installation lighting retrofit, an audit of other end-uses of households can be conducted. As footnotes $c, k$, and 0 in Table 4 indicate, other measures in the retrotit program include low-flow showerheads, low-flow faucetts, and water heater tank wraps for those customers that do not purchase solar water heaters. Although the energy savings is fairly small (i.e., $233 \mathrm{kWh} / \mathrm{year}$ ) but financially attractive (3.3 c/kWh CCE), a significant aspect of this program is the water savings that can be obtained. Conservatively estimating that 500 gallons of water can be saved annually by each participant translates into over 11 million gallons annually.

\subsubsection{Commercial and Industrial Programs}

In Table 5, we provide information for commercial and industrial DSM programs similar to that provided for residential programs in Table 4 with two major differences. 
Table 5

Key Variables for Commercial and holustrial Programs

U.S. Virgin lstands

\begin{tabular}{|c|c|c|c|c|c|c|c|c|}
\hline \multirow{2}{*}{ Category } & \multicolumn{4}{|c|}{ Time-of-Petirement Program } & \multicolumn{3}{|c|}{ Reirofit Programb } & \multirow{2}{*}{$\begin{array}{l}\text { Load } \\
\text { Mgm } \\
\text { Program }\end{array}$} \\
\hline & $\begin{array}{l}\text { Water } \\
\text { Heating }\end{array}$ & $\underset{\text { Conditioning }}{\text { Air }}$ & $\begin{array}{l}\text { Electric } \\
\text { Motors }\end{array}$ & Other & $\begin{array}{l}\text { Commercial } \\
\text { Lighting }\end{array}$ & $\begin{array}{l}\text { Industrial } \\
\text { Lighting }\end{array}$ & Other & \\
\hline $\begin{array}{l}\text { St. Thomas } \\
\text { Total Customers' } \\
\text { Customer Program Base } \\
\text { Cost per Participant } \\
\text { Savings per Participant (kWh) }\end{array}$ & $\begin{array}{l}4,332 \\
\pm * * \\
\star \star * \\
\star \star *\end{array}$ & $\begin{array}{l}4,332 \\
3,890^{\circ} \\
\$ 388^{h} \\
430^{h}\end{array}$ & $\begin{array}{l}4,332 \\
\ldots \neq * \\
* \star *\end{array}$ & $\begin{array}{l}4,332 \\
+ \pm * \\
t * *\end{array}$ & $\begin{array}{l}3,890 \\
3,890 \\
5526 \\
1,752\end{array}$ & $\begin{array}{c}442 \\
442 \\
\$ 10,126 \\
33,754\end{array}$ & $\begin{array}{c}4,332 \\
\pm \neq * \\
\pm \neq *\end{array}$ & $\begin{array}{l}4,332 \\
3,890^{\circ} \\
\$ 500 \\
5 \mathrm{~kW}\end{array}$ \\
\hline $\begin{array}{l}\text { St. Croix } \\
\text { Total Customers } \\
\text { Customer Program Base } \\
\text { Cost per Participant } \\
\text { Savings per Participant (kWh) }\end{array}$ & $\begin{array}{l}3,531 \\
\pm \neq \pm \\
\star \pm \star *\end{array}$ & $\begin{array}{c}3,531 \\
3,177^{\circ} \\
\$ 352^{n} \\
500^{n}\end{array}$ & $\begin{array}{l}3,531 \\
* \pm * \\
* \pm * \\
\pm * *\end{array}$ & 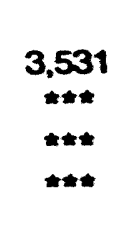 & $\begin{array}{l}3,177 \\
3,177 \\
5390 \\
1,299\end{array}$ & $\begin{array}{c}354 \\
354 \\
56,389 \\
21,298\end{array}$ & $\begin{array}{c}3,531 \\
\pm \# \\
\# * \\
\# *\end{array}$ & $\begin{array}{l}3,531 \\
3,177 \\
5500 \\
5 \mathrm{~kW}\end{array}$ \\
\hline $\begin{array}{l}\text { Common Program Characteristics } \\
\text { Maximum Participation (x) } \\
\text { Years to Attain Maximum } \\
\text { Conservation Load Factork } \\
\text { Cost of Conserved Energy (c/WWh) }\end{array}$ & 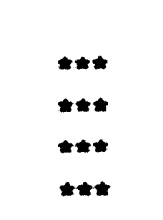 & $\begin{array}{l}75 \\
3 \\
40 \\
6.0\end{array}$ & $\underset{m *}{* \pm *}$ & $\underset{m \neq}{\infty \pm *}$ & $\begin{array}{l}90 \\
10 \\
40 \\
25\end{array}$ & $\begin{array}{l}90 \\
10 \\
40 \\
2.5\end{array}$ & 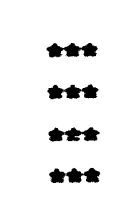 & $\begin{array}{l}50 \\
10 \\
10 \\
N A\end{array}$ \\
\hline
\end{tabular}

An entry of '***' means that reliable data are not currently available to quantily the parameters of this portion of the program.

The DSM measures under time-of-retirement programs are implemented when a new replacement durable is purchased-a.g., at the time the durable is depreciated.

'A retrofit program refers to house-to-house, direct installation of appropriate DSM measures by representatives of WAPA. 


\section{Table 5 (Cont)}

Includes only room air sonditioners and is based on the consenvative assumption that, on average, each commercial customer has one that will be retiredduring the planning period. Although significant energy savings likely exist for central air conditioners, sufficient data are not available to reasonably estimate the precise costs and savings for central air conditioners. Also, although savings are expected to be substantial, sufficient data do not exist to reasonably estimate the amount of savings for industrial customers.

Depending on the types of activities in the VI's commercial and industrial sectors, substantial savings could be realized from a program targeted at other types of durables such as refrigerators, stoves, and the like.

This portion of the retrofit program targets custom-tailored DSM measures for individual commercial and industrial establishments. Therefore, the types of retrofits and their cost and energy savings will be available only when audits are conducted.

'Customers as of June 30, 1992, the end of WAPA's fiscal year. Total customers for all measures except lighting are the sum of commercial and industrial customers.

'Because of data limitations, data includes only commercial customers.

"Assumption: one-half of the participants purchase a mini-split system (i.e., window 9.0 to mini-split 12.0); the other half purchase higherefficiency window units (i.e., 9.0 to 12.0). The incremental cost of the mini-split system is \$500; the incremental cost for the higherefficiency unit is $\$ 112$. Assuming WAPA pays one-half and a 15\% administration fee, the average cost to WAPA is $\$ 352$. Mini-splits Save $600 \mathrm{kWh}$ per year; high-efficiency air-conditioners save $400 \mathrm{kWh}$ per year. Assuming a $50-50$ split, the savings is $500 \mathrm{kWh}$ per year.

'Assumption: the cost of lighting savings for both commercial and industrial customers is \$300/MWh/year of energy savings.

'Assumption: lighting is $25 \%$ of the commercial-industrial load and $40 \%$ of this load can be saved through a lighting retrofit program. The average annual usage for commercial and industrial customers on St. Thomas is 17,522 kWh and $337,541 \mathrm{kWh}$, respectivety. The corresponding amounts for St. Croix are 12,986 kWh and 212,981 kWh.

"The ratio of average annual load savings to peak load savings for the DSM measure. 
First, the cost and amount of savings for the lighting measure are based on experiences elsewhere, rather than on specific retrofits. That is, as footnote $j$ indicates, we assume that lighting accounts for 25 percent of the electricity consumed in the commercial-industrial sector and that a direct-installation lighting measure can save 40 percent of this amount. Therefore, the lighting program can save 10 percent of the total electricity consumption of commercial and industrial customers that participate in the program.

Second, our knowledge of the penetration of electricity use in the commercialindustrial market and, therefore, the potential for energy savings is limited, accounting for the large number of starred entries in Table 5. A good example is the penetration of electric motors for industrial customers. On the U.S. mainland, electric motors account for two-thirds of electricity consumption in the industrial sector with a large potential for energy savings through use of more efficient electric motor systems. Using this as a reference, we surmise that there is a large potential for energy savings in the USVI. However, current data limitations preclude approximation of a program for this study.

Therefore, as shown in Table 5, we only quantify two measures for the commercial-industrial sector--one each for TOR and retrofit programs--recognizing that this vastly underestimates the potential for cost-effective DSM measures for these customers. For the cooling measure, we assume that one-tenth of conventional air conditioners are replaced each year. Therefore, 389 and 318 are replaced annually on St. Thomas and St. Croix, respectively. At 75 percent maximum participation after three years (Table 5), 292 and 238 customers are assumed to participate in the program (Appendix A.3). We conservatively assume that the average commercial customer has one window air conditioner. Again, as with the residential cooling measure, we only consider room air conditioners because the penetration of central air conditioners cannot be accurately estimated. And, we do not have information on the types of air conditioners used by WAPA's industrial customers.

Based on experiences elsewhere, commercial and industrial lighting measures rank toward the top in terms of financial attractiveness to electric utilities. Based on the CCE for these measures in Table 5, there is reason to believe that that should also be the case in the USVI. As noted above, we do not use a fixed number of bulbs or fixtures to estimate savings from the lighting measure. Father, based on experiences elsewhere, we assume that a lighting program will save 10 percent of average electricity consumption in the commercial and industrial sectors. For the commercial sector as Table 5 shows, this amounts to an annual savings of 1,752 and 1,299 kWh per customer for St. Thomas and St. Croix, respectively. The corresponding amounts are 33,754 and 21,298 for industrial customers. Again, based on experiences elsewhere, we assume that it will cost WAPA $\$ 300 / \mathrm{MWh} /$ year to achieve this savings. Given this expenditure, we assume that 90 percent of WAPA's commercial and industrial customers will participate in the program after 10 years (Table 5).

The load management program described in Table 5 is defined conservatively to cost $\$ 100$ per saved kilowatt. Assuming that $5 \mathrm{~kW}$ can be obtained from each participant on average, the total cost is $\$ 500 /$ participant. We assume that it takes 10 years of program operation to reach maximum participation of 50 percent. 'Ramping rates' and 
total program savings are defined in detail in Appendix A.5.

\subsubsection{New Construction Program}

The programs defined in Tables 4 and 5 apply to existing customers as of June 1992. In Table 6, we quantify key variables for a DSM program that applies to new construction after June 1992 for the residential and commercial rate classes. As Footnotes $b$ and $c$ indicate, we assume that the growth rate of new construction is onehalf of the annual average rate over the five-year period from 1987 through 1992 . For the residential sector, the cost per participant and energy savings for WAPA noted in Table 6 are the sums of the amounts for the solar water heating and cooling portions of the residential TOR program (Table 4). Again, quantities for the commercial sector are difficult to estimate with data currently available. 
Table 6

Key Variables for New Construction Programs

U.S. Virgin Islands

Category

Residential $^{\mathbf{a}}$

Commercial

St. Thomas/St. John

Total Customers

$145^{\mathrm{b}}$

$93^{b}$

Customer Program Base

145

93

St. Croix

Total Customers

$185^{\circ}$

$82^{c}$

Customer Program Base

185

82

Common Program Characteristics

Cost per Participant

$\$ 1,680^{d}$

$1,298^{\circ}$

75

Maximum Participation (\%)

Years to Attain Maximum

3

Conservation Load Factor'

50

Cost of Conserved Energy ( $(\mathrm{k} / \mathrm{kWh})$

4.7

$\star \star *$

$\star \star \star$

$\star \star \star *$

$\star \star \star$

$\star \star \star *$

$\star \star \star *$

An entry of ' $* \star{ }^{\prime}$ means that reliable data are not currently available to quantify the parameters of this portion of the program.

aThe solar water heating and cooling portions of the residential time-of-retirement program are included for newly constructed residences.

${ }^{b}$ Assumption: the growth rates of new construction in the residential and commercial sectors are assumed to be one-half the average annual five-year historical rate over the years 1987 to 1992 . The historical rates for the residential and commercial sectors over that five-year period are $1.5 \%$ and $4.8 \%$, respectively.

'Assumption: the growth rates of new construction in the residential and commercial sectors are assumed to be one-half the average annual five-year historical rate over the years 1987 to 1992 . The historical rates for the residential and commercial sectors over that five-year period are $2.0 \%$ and $5.2 \%$, respectively.

${ }^{d}$ The sum of costs of the solar water heating and cooling portions of the residential time-of-retirement program shown in Table 5, plus a 15\% administration fee.

The sum of the savings from the solar water heating and cooling portions of the residential time-ofretirement program shown in Table 5.

The ratio of average annual load savings to peak load savings of the DSM measure. 


\section{MODEL SIMULATIONS}

\subsection{DESCRIPTION OF SAFEPLAN}

A number of models have been developed to assess DSM and supply resources with varying degrees of analytical complexity and data requirements. Examples include the Multiobjective Integrated Decision Analysis System (MIDAS) developed for the Electric Power Research Institute (Temple, Barker, and Sloane, 1988), UPlan deveioped by the Lotus Consulting Group (1988), the Decision Impact Assessment Model (DIAMOND) developed by Oak Ridge National Laboratory (Gettings, Hirst, and Yourstone, 1991), and Scenario Analysis Framework for Expansion Planning (SAFEPLAN) (Policy Planning Associates, 1990). The more important characteristics of these models include (with possibilities):

- capacity expansion capability (yes, no); i.e., the capability to determine the optimal set of generating plant options, given assumptions about future load growth, fuel prices, and the like.

- treatment of time-of-use variations in demand (load duration curve, chronological); i.e., the extent to which the model allows the user to provide detail of changes in the load over 8,760 hours of the year on an hourly basis (chronological) or a more aggregated basis (an annual load duration curve).

- production costing routine (yes, no); i.e., the ability of the model to determine the optimal generation mix (loading order), given characteristics of existing generating units (e.g., the types and amount of capacity, fuel type, cost of fuel, hourly load).

- financial simulation module (yes, no); i.e., the model's ability to provide primary financial statements (i.e., the income statement, balance uheet, and flow-of-funds statements) and calculate important financial ratios (i.e., interest coverage ratio, present value of revenue requirements).

- treatment of uncertainty (yes, no); i.e., the model's capability to provide ranges for forecasts or expected values of important outputs.

The degree of complexity of a planning model--and user unfriendliness--is related to the manner in which each of these characteristics is treated. A model that has capabilities to:

- select an optimal mix of resources,

- characterize demand for 8,760 hours in every year of the planning horizon,

- determine the variable costs of employing supply-side resources,

- simulate the financial performance of the utility, and

- include uncertainties in resource selection 
tends to be very large ar $d$ complex with significant data requirements. Selection of a model for any purpose, of course, depends on the uses to which the model is to be put.

SAFEPLAN was selected because it satisfied the requirements of this study. The model facilitates developing multiple plans, minimizing data requirements.

In Figure 4, we show how cost-benefit ratios are calculated for any DSM or supply resource in SafePlan. The costs of a project are the sum of capacity and energy costs. Capacity costs are the present value of the time stream of construction expenditures providec' for each candidate resource. They are applicable only for those projects that take multiple periods to construct. In the WAPA simulations discussed below, the only project that is multiperiod is the combustion turbine. We assume that it takes three years to construct with a 20-20-60 apportionment of the construction costs. The assumed discount rate is 10 percent.

Figure 4

Calculation of Cost-Benefit Ratios in SafePlan

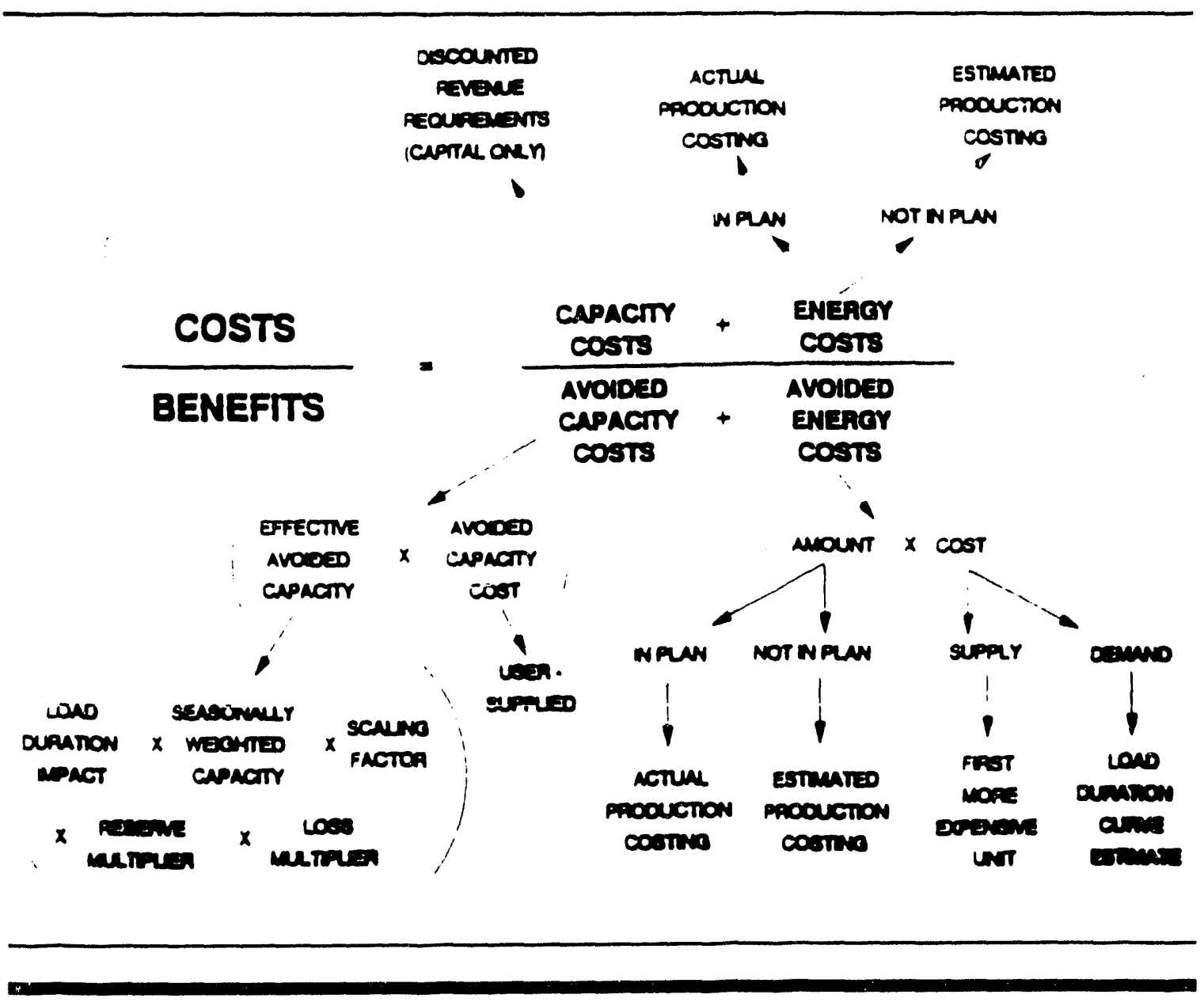


Actual energy costs for a project are determined by economic dispatch in the production costing model. For resources not included in the current plan, energy costs are estimated from units that were included in the dispatch. The capacity utilization factor of the next more expensive unit in the dispatch is used to determine the amount of energy assigned to the project. If a candidate resource is more expensive than the last unit, it is assigned the capacity utilization factor of the last unit. To determine energy costs, these running rates are multiplied by the variable costs of the candidate resources provided by the user. For that combustion turbine, we assumed a fixed O\&M cost of $\$ 2.00$ per kilowatt of installed capacity. The fuel cost is scenario-based and discussed in detail below.

Calculating the two avoided cost components is more complex. Avoided capacity costs are the product of a user-supplied avoided capacity value (in this case, a combustion turbine) and effective avoided capacity. The latter is the product of several factors as shown in Figure 4 and is important in determining the capacity contribution of DSM resources. That is, because DSM resources reduce capacity requirements, they also reduce corresponding reserve requirements. In our simulations, we assume that WAPA requires a 33 percent reserve margin because of its inability to purchase power from neighboring utilities. Therefore, from Figure 4, the reserve multiplier is 1.33 for an DSM resource: a kilowatt of supply capacity is worth $1.33 \mathrm{~kW}$ if obtained from a DSM program. Similarly, avoiding construction of one $\mathrm{kW}$ of capacity through a DSM program reduces technical losses of transmitting and distributing electricity. We assume a 15 percent loss factor; therefore, from Figure 4, the loss multiplier is 1.15.

Avoided energy costs are estimated as the cost of supplying energy with other resources in the plan. They are the weighted average of the costs of units that have available generation and are more expensive than the candidate resource. Each candidate resource, therefore, has a unique avoided cost. For avoided energy costs of supply resources, the "first more expensive unit" in Figure 4 is the utilization-weighted average cost of under-utilized, more expensive units. The avoided energy costs of candidate DSM resources are estimated using their effects on the load duration curve.

\subsection{FIVE SCENARIOS}

In Table 7, we provide the growth in fuel prices, the growth in peak load, and the treatment of environmental externalities for five scenarios that were simulated in the study. For each of the five scenarios, the assumed values of two important variables did not change: the system load factors and the capacity cost of the avoided generating unit (i.e., the combustion turbine). The system load factor is defined in a manner similar to the conservation load factor defined in Tables 5,6 , and 7 : it is the ratio of average load (i.e., $\mathrm{kWh}$ generated divided by 8,760 hours) to peak load. The capacity cost of the avoided generating unit is important. In determining the cost-effectiveness of different resource options, it determines the avoided capacity costs of the benefits of employing a resource (see Figure 4). Throughout this study, we use a combustion turbine as the avoided unit. That combustion turbine costs $\$ 400$ per kW (1992 dollars) and, therefore, has an annual 
cost of $\$ 30 / \mathrm{kW}^{2}$. The fuel costs for this avoided unit, of course, are the same ones used for existing units.

Table 7

Definition of Scenarios for Model Simulations

St. Thomas and St. Croix

\begin{tabular}{|c|c|c|c|}
\hline Scenario & $\begin{array}{l}\text { Fuel } \\
\text { Prices } \\
\text { (\%/Year) }\end{array}$ & $\begin{array}{c}\text { Poak } \\
\text { Load } \\
\text { (\% Growth) }\end{array}$ & $\begin{array}{c}\text { Externalities } \\
\text { (Scenario) }\end{array}$ \\
\hline $\begin{array}{l}\text { No Fuel Price Increases }{ }^{a} \\
\text { ElA Fuel Price Forecasts } \\
\text { High Fuel Price Increases } \\
\text { High Load Growth } \\
\text { Environmental Externalities }\end{array}$ & $\begin{array}{l}0 \\
2.0 \\
4.0 \\
2.0 \\
2.0\end{array}$ & $\begin{array}{l}2.3 \\
2.3 \\
2.3 \\
3.3 \\
2.3\end{array}$ & $\begin{array}{l}\text { None } \\
\text { None } \\
\text { None } \\
\text { None } \\
15 \% \text { Adder }\end{array}$ \\
\hline
\end{tabular}

"Assumes that real fuel prices do not increase over the forecast perlod.

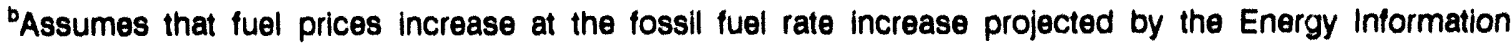
Administration (EIA).

'Assumes that fuel prices increase at two times the rate of growth forecasted by ElA.

'Assumes that peak load grows at one percentage point higher rate of growth than that projected by WAPA.

Includes $15 \%$ additional cost for environmental externalities, increasing the cost of producing electricity using fossil fuel generating units.

The five scenarios were devised to look at the effects of three factors on resource selection: (1) the cost of fuel prices for generating electricity, (2) the projected growth in electric load, and (3) the effect of accounting for externalities in resource selection. The base scenario is the the second one: fuel prices increase at the real rate of 2.0 percent per year, electric load for both St. Thomas and St. Croix grows at WAPA's forecasted rate (2.3 percent per year on average), and environmental externalities are not considered.

The major feature of the first scenario is that the real price of No. 2 and No. 6 fuel

\footnotetext{
${ }^{2}$ This annual charge can be viewed as delaying the construction of a combustion turbine for one year indefinitely into the future. Therefore, it is the difference between the net present value of revenue requirements for a combustion turbine placed in operation this year and that same unit placed in operation next year. To see the importance of this value in determining the cost-effectiveness of resources under consideration, a 600 MW coal plant at $\$ 1,600$ per kilowatt has an annual capacity cost of $\$ 120 / \mathrm{kW}$.
} 
for generating electricity does not increase. Peak load growth over the next 20 years is that provided by WAPA (U.S. Energy Information Administration, 1991). Characteristics of DSM programs for this scenario are provided in Tables 5 through 7.

In the second scenario, we look at the effect of rising fuel prices on the costeffectiveness of different resources. Therefore, we use the Energy Information Administration's forecast of fossil fuel price increases over the 20-year planning horizon. Under this forecast, the prices of these fuels grow at the annual rate of 2.0 percent over the planning horizon. For the third scenario, we examine very high fuel price growth rates, doubling EIA's forecast to a 4.0 percent annual rate over the 20 -year horizon.

In the fourth scenario, we keep ElA's fuel price forecasts, but increase WAPA's projected load growth figures. For St. Thomas, we use an annual average load growth of 2.3 percent for the summer peak from 66.0 MW in June 1992 to $97.8 \mathrm{MW}$ in June 2012 and 2.3 percent for the winter peak from 59.7 MW in February 1993 to $92.1 \mathrm{MW}$ in February 2013. These growth rates were used for the first three scenarios. In the fourth scenario, we increase St. Thomas' 20-year summer peak growth to 121.4 MW (3.3 percent average annual growth) and the winter peak to $114.8 \mathrm{MW}$ (also a 3.3 percent average annual growth). The average annual percentage increases for St. Croix are similar. Summer peak load is $74.2 \mathrm{MW}$ in September 2012. The corresponding amount for the winter peak in December is 71.7 .

The fifth scenario addresses the question of environmental externalities. Here, we add environmental costs to the operating costs of existing and future fossil fuel plants. Rather than quantifying the cost of each of the effluents, we use a 'percentage adder' of 15 percent. As discussed in Section 1.2.3, the adder approach is one of three used by electric utilities. The 15 percent is one that has been used in Wisconsin (Wisconsin Electric Power Conipany, 1988). The effect of including environmental externalities, of course, is to increase the operating cost of fossil units, making them relatively more unattractive in the resource selection process in comparison with alternatives that do not use fossil fuels.

\subsection{SIMULATION RESULTS}

\subsubsection{Five Scenarios}

In Table 8, we provide the cost:benefit ratios of the DSM measures that were calculated in SafePlan. ${ }^{3}$ Several conclusions emerge from the data in the table.

First, although the DSM measures were defined similarly for each of the islands (see Tables 5 through 7), their cost-effectiveness differs on St. Thomas and St. Croix. The reasons, of course, are due to differences in the operating characteristics of the two islands.

Second, cost-effectiveness varies across scenarios. For example, the residential

\footnotetext{
${ }^{3}$ For details of the calculation, see the discussion in Section 5.1 in the context of Figure 4
} 
Teble 8

Cost-Benefit Ratios for DSM Programs from Model Simulations

Modeling Simulation Scenario

Area/Measures

\begin{tabular}{|c|c|c|c|c|}
\hline $\begin{array}{l}\text { No Fuel } \\
\text { Increases }\end{array}$ & $\begin{array}{l}\text { ElA Fuel } \\
\text { Increases }\end{array}$ & $\begin{array}{l}\text { High Fuel } \\
\text { Increases }\end{array}$ & $\begin{array}{l}\text { High Load } \\
\text { Growth }\end{array}$ & $\begin{array}{l}\text { Emironmental } \\
\text { Externalities }\end{array}$ \\
\hline
\end{tabular}

St Thomas

Residential Water Heating

0.90

0.22

0.58

Residential Cooling

Residential Retrofit

Residential New Construction

1.22

Commercial Air Conditioning

1.01

0.43

Commercial Lighting

Industrial Lighting

Load Management

0.43

0.32

0.69

0.17

0.45

0.92

0.78

0.33

0.33

0.24

0.52

0.71

0.61

St. Croix

Residential Water Heating

Residential Cooling

Residential Retrofit

Residential New Construction

Commercial Air Conditioning

Commercial Lighting

Industrial Lighting

Load Management

$\begin{array}{ll}0.96 & 0.72 \\ 0.19 & 0.14 \\ 0.48 & 0.36 \\ 1.01 & 0.75 \\ 0.83 & 0.62 \\ 0.35 & 0.26 \\ 0.35 & 0.26 \\ 0.31 & 0.23\end{array}$

0.13

0.18

0.15

0.34

0.47

0.40

0.69

0.96

0.82

0.35

0.25

0.25

0.35

0.25

0.69

0.29

0.20

0.22

The DSM meesures are defined in Tables 5-7. 
cooling DSM measure on St. Thomas is clearly cost-ineffective under the 'no fuel increases' scenario-...e., a cost benefit ratio of 1.28. However, as fuel prices are assumed to increase--l.e., as the cost of providing electricity from a combustion turbine increases.the residential cooling option becomes more attractive. It is a borderline option under the 'ElA fuel increases' scenario (cost:benefit of 0.99 ) and clearly cost-effective under the 'high fuel increases' scenario. Similar arguments can be made for other DSM measures under different scenarios.

Third, the commerclal and industrial lighting measures and the load management programs on the two islands are the clearly the most cost-effective DSM measures. Under the worst-case scenario for DSM measures--1.e., no increases in the real price of No. 2 and No. 6 fuel--those three measures are almost the only cost-effective measures on St. Croix (the residential water healing measure is the exception) and the three most cost-effective on St. Thomas. As restrictive fuel-price and load-growth assumptions are relaxed, these three measures become even more attractive from the standpoint of resource acquisition. The cost-effectiveness of these three measures is generally consistent with that which is found in the experiences of other utiities.

In Table 9, we summarize the simulation results for St. Thomas and St. Croix for the five scenarios. The dollar values are the present value of the costs of satistying WAPA's electric load from 1993 to 2012 with cost-effective DSM programs included in the analysis and with cost-effective DSM programs excluded. In the 'without DSM' simulations, we use only a 22-MW combustion turbine to satisty WAPA's projected load. In the 'with DSM' simulations, we implement cost-effective DSM programs in 1993 (i.e., based on the ratios in Table 8) until all eight programs are exhausted or capacity and energy requirements are met--whichever comes first. Any remaining load requirements are met by constructing combustion turbines.

The results in Table 9 show that including cost-effective DSM programs to satisty future load requirements has a significant impact on the cost of providing electricity services, irrespective of the assumptions made about fuel price growth, load growth, and environmental externalities. Put simply, this means that, under all scenarios, the cost of conserved energy for the cost-effective measures is less than WAPA's avoided cost of power. The avoided cost, of course, is based on simulations of the system using SafePlan. The cost savings are greater on St. Thomas because there are more electric customers and electricity consumption is larger on these islands than St. Croix and, therefore, the potential for DSM programs is greater. The largest amount of savings are associated with a higher assumed load growth ('high load growth' scenario) because more cost-effective DSM programs can be implemented with higher levels of load growth. From Table 9, the difference between present value of costs without DSM measures and the value of costs with DSM measures is $\$ 163.6$ million over the 20-year planning horizon.

The energy savings resulting from implementing DSM measures and their contributions to capacity under the five scenarios are presented in Table 10. One of the main reasons for the decline in the percentage contribution of DSM measures from 2002 to 2012 is the assumption that the initial savings in many DSM measures declines over the 20-year planning period after the life of the energy-efficient durable expires. The assumption is that WAPA runs DSM programs to capture the initial market. It does not 
Table 9

Cod Sevinge from Running DSM Programs

8t. Thomes and St. Crobx

(in Mullion of 1902 Dollare)

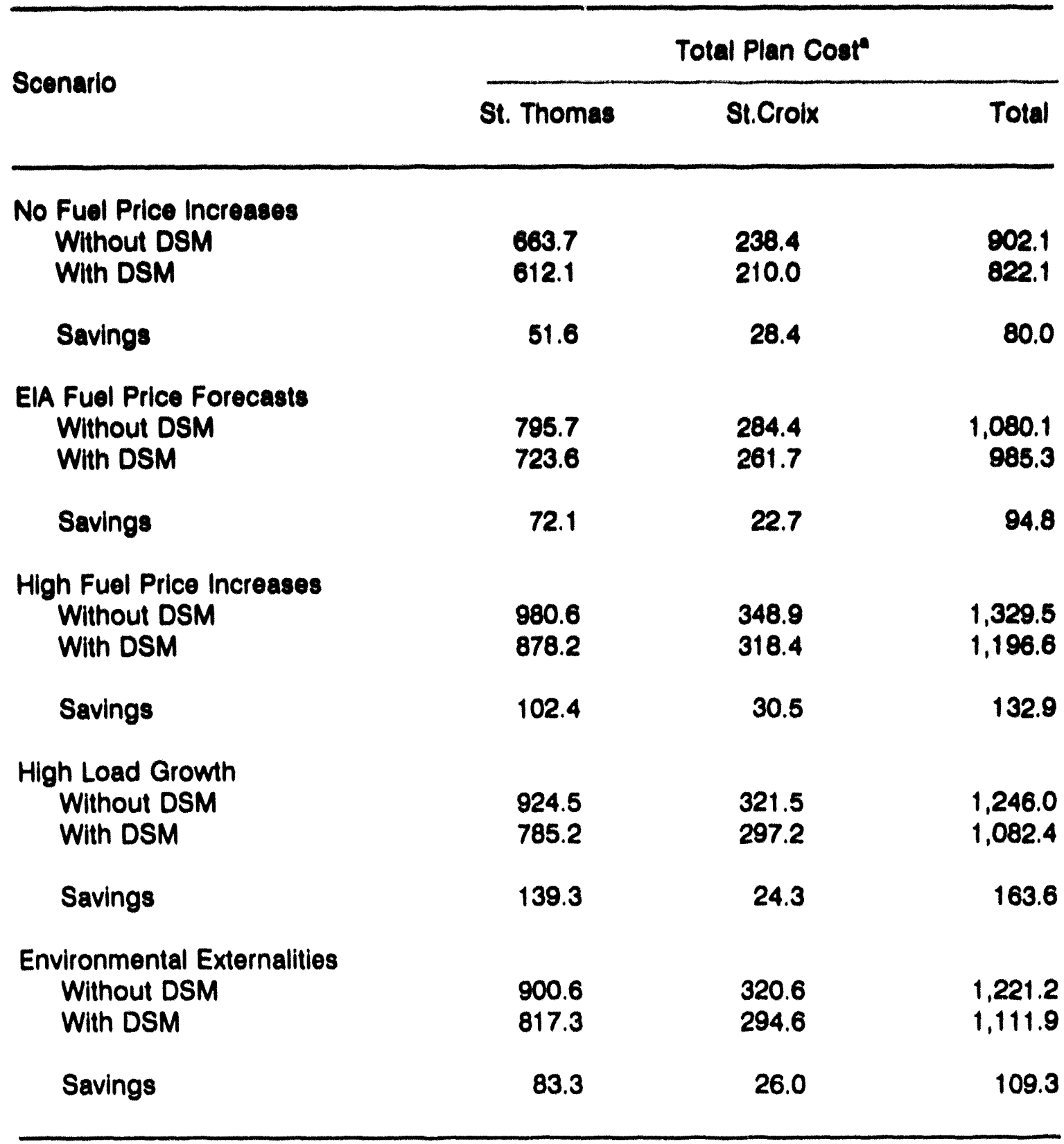

-The net present value of the incremental cost of servicing electric load over the 20-year planning horizon. 
Table 10

Energy and Capactly Contributions of DSM Programe

St. Thomes and St. Crobx

2002 and 2012

(in Percentegen)

\begin{tabular}{|c|c|c|c|c|}
\hline \multirow{2}{*}{$\begin{array}{l}\text { Scenario/ } \\
\text { Region }\end{array}$} & \multicolumn{2}{|c|}{ Energy" } & \multicolumn{2}{|c|}{ Capacity" } \\
\hline & 2002 & 2012 & 2002 & 2012 \\
\hline $\begin{array}{l}\text { No Fuel Price } \\
\text { St. Thomas } \\
\text { St. Crolx }\end{array}$ & $\begin{array}{l}9.4 \\
6.9\end{array}$ & $\begin{array}{l}5.6 \\
3.6\end{array}$ & $\begin{array}{l}100.0 \\
100.0\end{array}$ & $\begin{array}{r}53.6 \\
100.0\end{array}$ \\
\hline Total & 8.5 & 4.8 & 100.0 & 65.1 \\
\hline $\begin{array}{l}\text { ElA Fuel Price } \\
\text { St. Thomas } \\
\text { St. Croix }\end{array}$ & $\begin{array}{r}10.2 \\
6.9\end{array}$ & $\begin{array}{l}6.5 \\
3.6\end{array}$ & $\begin{array}{l}100.0 \\
100.0\end{array}$ & $\begin{array}{r}55.6 \\
100.0\end{array}$ \\
\hline Total & 8.9 & 5.4 & 100.0 & 66.3 \\
\hline $\begin{array}{l}\text { High Fuol Pric } \\
\text { St. Thomas } \\
\text { St. Crolx }\end{array}$ & $\begin{array}{r}10.2 \\
6.9\end{array}$ & $\begin{array}{l}6.5 \\
3.6\end{array}$ & $\begin{array}{l}100.0 \\
100.0\end{array}$ & $\begin{array}{r}55.6 \\
100.0\end{array}$ \\
\hline Total & 8.9 & 5.4 & 100.0 & 66.3 \\
\hline $\begin{array}{l}\text { High Load Gro } \\
\text { St. Thomas } \\
\text { St. Croix }\end{array}$ & $\begin{array}{r}9.0 \\
11.8\end{array}$ & $\begin{array}{l}5.1 \\
7.3\end{array}$ & $\begin{array}{l}100.0 \\
100.0\end{array}$ & $\begin{array}{l}38.1 \\
50.9\end{array}$ \\
\hline Total & 10.0 & 5.9 & 100.0 & 43.1 \\
\hline $\begin{array}{l}\text { Environmenta } \\
\text { St. Thomas } \\
\text { St. Croix }\end{array}$ & $\begin{array}{l}9.7 \\
6.9\end{array}$ & $\begin{array}{l}6.5 \\
3.6\end{array}$ & $\begin{array}{l}100.0 \\
100.0\end{array}$ & $\begin{array}{r}55.6 \\
100.0\end{array}$ \\
\hline Total & 8.7 & 5.4 & 100.0 & 66.3 \\
\hline
\end{tabular}

-The pontion of total energy and capacity accounted for by DSM programs. 
run programs over the 20-year planning horizon. The savings for each of the DSM measures on each of the islands is provided in detail in Appendix $A$.

The results in Table 10 are consistent with the cost savings provided in Table 9. For example, the largest amount of energy savings comes under the high load growth scenario where cost-effective DSM programs have a better opportunity to be adopted because of higher energy and capacity requirements. Again, the results in Table 10 understate the energy savings and capacity contributions of DSM programs because many expected cost-effective DSM programs were not defined. ${ }^{4}$

\subsubsection{Wind Generation as a Resource Option}

Wind as an electric generating resource option was not compared with a combustion turbine and DSM measures in all of the simulations. One of the primary reasons was data limitations. Ideal wind generation sites were not determined at the time of running of the simulations. Those sites are crucial for cost determination because of the high cost of land in the USVI relative to other regions where the data has been gathered on wind generation.

However, based on experiences elsewhere, the parameters of a wind generating resource were quantified and varied to look at the potential for wind as a future generating option. The wind resource under consideration was $250 \mathrm{~kW}$ with a total installed capacity cost of $\$ 253,250$. Net annual energy from the turbines is $438 \mathrm{MWh}$. It has a fixed O\&M cost of $\$ 8.00 / \mathrm{kW}$ and $0.7 \mathrm{q} / \mathrm{kWh}$ variable $0 \& \mathrm{M}$ cost. A wind turbine with $125 \mathrm{~kW}$ capacity is assumed to require 0.75 acres of land. The capacity factor of the plant is 20 percent. The plant has a 20 -year life.

The cost:benefit ratio for this wind system on St. Thomas was simulated to be 0.66 under the base scenario (EIA fuel price increases). Doubling the capital cost makes the system cost ineffective: 1.27 cost:benefit ratio. Doubling the O\&M cost, but holding capital cost constant results in a 0.71 ratio. Doubling both the capital and operating cost components, of course, results in a 1.32 cost:benefit ratio.

\footnotetext{
${ }^{4}$ See the starred entries in Tables 5 through 7 for details of the DSM measures that were not considered in the simulations because of data limitations.
} 


\section{RECOMMENDATIONS}

In this study, we suggested some alternatives to constructing and operating combustion turbine electric generating plants to satisty future electric energy and load requirements in the USVI. The economic attractiveness of the suggested alternatives was based on a rigorous comparison of their costs and benefits.

The key point to remember is that IRP is not a one-time study. Rather, it is a continuing process, the exact procedures of which for a given utility evolve over time. Although undertaken with the cooperation and assistance of WAPA staff, this assessment was largely conducted at ORNL. It should be viewed as the springboard for IRP activities, not an end in itself. Three types of activities should be pursued to develop WAPA's capability to properly compare DSM and supply resources:

- Familiarization with IRP,

- Information gathering,

- Resource comparison.

\subsection{FAMILIARIZATION WITH IRP}

It would be beneficial to have two separate levels of familiarization: one at the executive level and the other for staff members of WAPA and other government agencies. The executive presentation should last a maximum of one-half day and should include an overview of the two components of the IRP process--least-cost planning and demand-side planning--and how they are used together as an analytical tool. The benefits to the USVI from achieving lower-cost electricity services should be identified, and their prospective magnitudes presented so that decisionmakers can understand the potential contribution IRP could make to achieving their goals. The presentation should also include a discussion of the social costing of resources. It should also include the experience of other utilities with IRP: motivation for IRP, reporting requirements, the extent of usage, and the benefits obtained from its use. Ideally, there would be several speakers at the session, representing research, utility, and regulatory experiences.

Once the IRP process is adopted, there should be an intensive series of sessions on detailed aspects of its implementation. These sessions should be attended by the practitioners and their managers, rather than executives. This portion of the training would last no more than one week, and again include both utility and regulatory perspectives. The IRP familiarization would ideally be organized around five topics:

- Least-cost planning

This session would discuss conceptual and pragmatic issues in analyzing the optimal mix of supply resources.

- Demand-side management

This session would cover three areas: (1) methods to develop DSM programs, including data requirements; (2) the process of implementing DSM programs; and (3) the 
process of evaluating DSM programs.

- Social costing of resources

The environmental (and other) externality debate is introduced in this session. The discussion includes the types of approaches that can be used to incorporate externalities into decisionmaking, along with the experiences of electric firms in other parts of the world.

- Integrated resource planning

This portion will cover two areas: (1) existing models to compare DSM and supply resources and (2) important factors to consider when comparing them, including differences in their financial, economic, and reliability characteristics.

- Conservation Technologies

This portion of the training would introduce the engineering aspects of energyefficiency improvements, including the types of off-the-shelf technologies that are currently available and the energy savings likely to result from their use.

\subsection{INFORMATION GATHERING}

In Section 4, we pointed out the types of data needed to implement the IRP process and data requirements for designing, implementing, and evaluating DSM programs. In fact, a good starting point in understanding the types of data needed is the information provided in Tables 5,6 , and 7 of Section 4 , especially the program assumptions provided in the footnotes to those tables.

Ideally, data are needed on electricity consumption by end use (e.g., lighting, refrigeration). Data are also needed on the customer base of the programs. How many potential customers will particpate in a commercial lighting program? A residential solar water heating program? Data is also required on the resource base for renewable supply options. Besides quantities, many other types of information are required. Many of them relate to the institutional structure of the USVI. For example, information on the possibility of using different financing mechanisms for DSM programs is required. The ownership of the housing stock must also be considered (e.g., public vs. private housing). These types of data, however, are not routinely collected by government agencies in the USVI or WAPA.

Several methods can be used to collect the type of information required to implement an IRP process. First, customers can be metered to accurately quantify enduse consumption. The on-going metering in the renewable energy district in Frederiksted should provide important information here. Lacking funds or time to meter, another method is a survey of electricity customers on their consumption patterns and durable ownership. Finally, a controlled experiment in the form of a pilot program has been used extensively by many mainland utilities. The information obtained from the pilot is then used to develop a program for the entire island. 


\subsection{RESOURCE INTEGRATION}

The third activity is the heart of the process: resource comparison. The activity involves procuring and adapting a model to systematically assess the different financial, economic, and reliability dimensions of DSM and supply resources. The outcome of the process is a plan or strategy for employing resources in the future. There should be a short-term action plan produced which requires the immediate attention of WAPA and other policymakers. The second output of the process is a long-term integrated resource plan spanning a 15- to 20-year period. This plan provides a resource road map for policymakers.

Changing conditions external to WAPA (e.g., changing fuel input prices, electricity demand growth rates, and the costs of financing) suggest that IRP is not a one-time study, but rather a continuing process. An appreciable change in any one of these variables can alter the relative cost-effectiveness of resources. Recognizing the dynamics of this process, another recommendation is that IRP be institutionalized at WAPA. One method is to have regular plan updates. For example, a common practice with utilities on the mainland is to perform a full-scale, integrated resource plan every three years. However, in the intervening two years, the utilities are required to update the plan based on changing external circumstances.

Because IRP is a continuing process, we also recommend that changes be made in the organizaticinal structure of WAPA to accommodate the process. One approach used on the mainland is to organize around the IRP process using a team concept, drawing upon appropriate staff from all departments within the utility. The center of the process, an integration team, takes input from a demand-side team and a supply-side team. The integration team is ultimately responsible for developing the integrated plan. 


\section{REFERENCES}

Beck and Associates, 1987, Electric Cost of Service Study for the Virgin Islands Water and Power Authority, Denver, Colorado, September.

Beck and Associates, 1990, Long-Range Electric Generation Expansion Plan for St. Croix, Denver, Colorado.

Beck and Associates, 1989, Long-Range Electric Generation Expansion Plan for St. Thomas and St. John, Denver, Colorado.

Beck and Associates, 1991, Integrated Solid Waste Management Plan, Denver, Colorado, June.

California Public Utilities Commission and California Energy Commission, Standard Practice Manual: Economic Analysis of Demand-Side Management Programs, December 1987.

Conservation Law Foundation, 1990, Power by Efficiency: An Assessment of Improving Electrical Efficiency to Meet Jamaica's Power Needs, June.

Gettings, Michael, Eric Hirst, and Evelin Yourstone, 1991, Diamond: A Model of Incremental Decision Making for Resource Acquisition by Electric Utilities, Oak Ridge National Laboratory, Oak Ridge, Tennessee, ORNL/CON-315, February.

Hill, Lawrence J., 1990, Electricity Pricing as a Demand-Side Management Strategy: Western Lessons for Developing Countries, Oak Ridge National Laboratory, Oak Ridge, Tennessee, ORNL-6620, December.

Hill, Lawrence J., 1991a, "Can Developing Countries Benefit from Innovative Pricing in the Power Sector?," Natural Resources Forum, 15(1), pp. 15-25, February.

Hill, Lawrence J., 1991b, "Large Power Users and Capacity Shortages in Developing Countries: The Role of Innovative Pricing," International Journal of Global Energy Issues, 3(2), pp. 86-96.

Hill, Lawrence J., 1991c, "Residential Time-of-Use Pricing as a Load Management Strategy: Effectiveness and Applicability," Utilities Policy, 1(4), pp. 308-318, 1991.

Hill, Lawrence J., 1992, "Pricing Initiatives and Development of the Korean Power Sector: Policy Lessons for Developing Countries," Energy Policy, 20(4), pp. 344-354, April.

Hill, Lawrence J., 1993, "Integrating Methods and Resource Selection in Electric-Utility Planning," Utilities Policy, 3(1), pp. 57-61, January.

Hill, Lawrence J., William F. Barron, Phil LaRocco, Milton Russell, and Zhongmin Shen, A Prefeasibility Study of Energy Resource Options in Hainan, China, Oak Ridge National Laboratory, Oak Ridge, Tennessee, ORNL/TM-12182, October 1992. 
Hill, Lawrence J., Eric Hirst, and Martin Schweitzer, 1991, Integrating Demand-Side Management Programs into the Resource Plans of U.S. Electric Utilities, Oak Ridge National Laboratory, Oak Ridge, Tennessee, ORNL/CON-311, January (also published by the Electric Power Research Institute, Palo Alto, California, EPRI TR-100255, December 1991).

Hill, Lawrence J., Eric Hirst, and Martin Schweitzer, 1992a, "From DSM Technologies to DSM Programs: Issues in Demand-Side Planning for Electric Utilities," Energy, The International Journal, 17(2), pp. 151-160.

Hill, Lawrence J., Eric Hirst, and Martin Schweitzer, 1992b, "The Process of Integrating DSM and Supply Resources in Electric Utility Planning," Utilities Policy, 2(2), pp. 100-107, April.

Hill, Lawrence J., Eric Hirst, and Martin Schweitzer, 1992c, "How Electric Utilities Plan Bemand-Side Management Programs, "Strategic Planning for Energy and the Environment, 2(4), pp. 23-34, Spring.

Jamaica Bureau of Standards, 1992, Jamaica National Building Code: Energy Efficiency Building Code, EEBC-92, Kingston, Jamaica, February.

Laitner, Skip and Greg Holmes, 1993, "The Energy Policy Act of 1992: Mandates and Opportunities in the U.S. Virgin Islands," Economic Research Associates, Eugene, Oregon, February, Draft.

Lotus Consulting Group, 1988, UPlan, The Electric Utility Planning System, Los Altos, California.

Policy Planning Associates, 1991, SAFEPLAN (Scenario Analysis Framework for Expansion Planning): Users' Manual, Kirkland, Washington.

Schweitzer, Martin, Eric Hirst, and Lawrence J. Hill, 1991, Demand-Side Management and Integrated Resource Planning: Findings from a Survey of 24 Electric Utilities, Oak Ridge National Laboratory, Oak Ridge, Tennessee, ORNL/CON-314, Forthcoming.

Tahal Consulting Engineers, Ltd., 1991, Virgin Islands Water and Power Authority: Engineer's Certificate and Report of Inspection and Review of the Water Supply Systems, Tel Aviv, Israel, No. R-91-28, November.

Tahal Consulting Engineers, Ltd., 1991, Virgin Islands Water and Power Authority: Potable Water Demand Study for St. Croix, U.S.V.I., Tel Aviv, Israel, No. R-91-23, November.

Temple, Barker, and Sloane, 1988, Multiobjective Integrated Decision Analysis System (MIDAS), Vol. 1: Model Overview, Electric Power Research Institute, Palo Alto, California, EPRI P-5402, April.

U.S. Department of Commerce, 1989, 1987 Economic Censuses of Outlying Areas: Virgin Islands of the United States Washington, D.C., OA87-E-5, September. 
U.S. Energy Information Administration, 1991, Annual Electric Control and Planning Area Report: U.S. Virgin Islands, Washington, D.C., Form ElA-714.

Wisconsin Electric Power Company, 1988, Advance Plan 5, Revised Filing, Milwaukee, Wisconsin, May 25. 
APPENDIX A

TECHNICAL DSM PROGRAMS 
A.1. RESIDENTIAL TIME-OF-RETIREMENT PROGRAM 
Residential Water Heating Program--St. Thomas

\begin{tabular}{c} 
Participation \\
\hline x Mew Total
\end{tabular}

Total

Savings

1993

$1994 \quad 2$

19953

1996

1997

1998

1999

2000

2001

2002

2003

2004

\%

$\begin{array}{rrrr}25 & 458 & 458 & \pi 7 \\ 50 & 915 & 1,373 & 2,331 \\ 75 & 1,373 & 2,745 & 4,662 \\ 75 & 1,373 & 4,118 & 6,992 \\ 75 & 1,373 & 5,491 & 9,323 \\ 75 & 1,373 & 6,863 & 11,654 \\ 75 & 1,373 & 8,236 & 13,985 \\ 75 & 1,373 & 9,609 & 16,316 \\ 75 & 0 & 9,609 & 16,316 \\ 75 & 0 & 9,609 & 16,316 \\ 75 & 0 & 9,609 & 16,316 \\ 75 & 0 & 9,609 & 16,316 \\ 75 & 0 & 9,609 & 16,316 \\ 75 & 0 & 9,609 & 16,316 \\ 75 & 0 & 9,609 & 16,316 \\ 75 & 0 & 9,609 & 16,316 \\ 75 & 0 & 9,609 & 16,316 \\ 75 & 0 & 9,609 & 16,316 \\ 75 & 0 & 9,609 & 16,316 \\ 75 & 0 & 9,609 & 16,316\end{array}$

rotal
Cost
$(\$ 000)$
448
897
1,345
1,345
1,345
1,345
1,345
1,345
0
0
0
0
0
0
0
0
0
0
0
0

2012

\section{per year (1/8*14642)}

$\begin{array}{lrl}\text { Customer Base } & 1,830 & \text { per year (1/\% } \\ \text { Cost/Cust. } & \$ 980 & \text { (\$850 + 15X dinistration fee) }\end{array}$

kth

Savings/Cust.

0.6

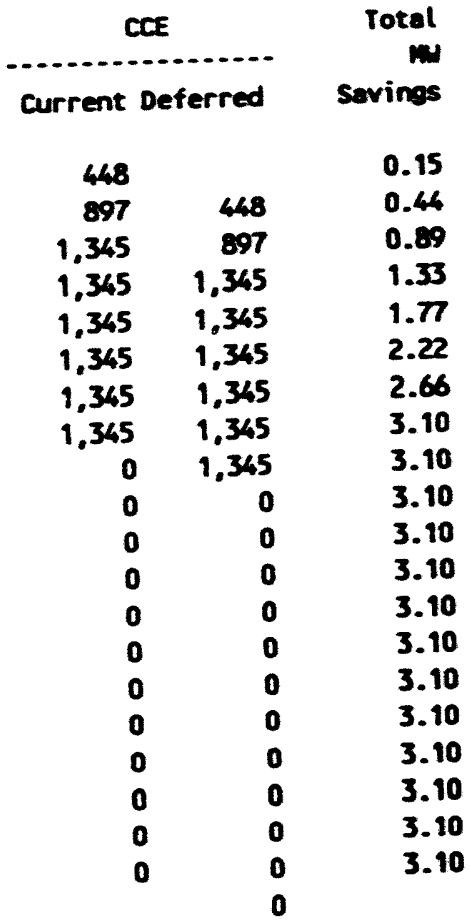

$5,999 \quad 5,466 \quad \cdots-$ Met Present Value

545 -..5000 Sevings

13,091 -.-Avg. mh Servines

$4.2 \cdots-\cos$ 
Residential Water Meating Progran--St. Croix

\begin{tabular}{c} 
Participation \\
\hline$x$ New Total
\end{tabular}

Total

Sevines

$\begin{array}{rr}1993 & 1 \\ 1994 & 2 \\ 1995 & 3 \\ 1996 & 4 \\ 1997 & 5 \\ 1998 & 6 \\ 1999 & 7 \\ 2000 & 8 \\ 2001 & 9 \\ 2002 & 10 \\ 2003 & 11 \\ 2004 & 12 \\ 2005 & 13 \\ 2006 & 14 \\ 2007 & 15 \\ 2008 & 16 \\ 2009 & 17 \\ 2010 & 18 \\ 2011 & 19 \\ 2012 & 20\end{array}$

25
50
75
75
75
75
75
75
75
75
75
75
75
75
75
75
75
75
75
75

425
1,25
1,275
1,275
1,275
1,275
1,27

414
1,264
2,539
3,815
5,090
6,365
7,611
8,916
8,916
8,916
8,916
8,916
8,916
8,916
8,916
8,916
8,916
8,916
8,916
8,916

703
2.147

2,147

6,477

8,643

10,800

12,974

15,139

15,139

15,139

15,139

15.139

15,139

15,130

15.139

15,139

15,139

15,139

15,139

15,139

\section{Customer Base} Cost/cust.

1,700 per year (1/8n13603)

Sovines/Cust.

5000

(ses0 + $15 x$ aduinistration Fee)

wh

CLF

0.6

\begin{tabular}{|c|c|c|c|}
\hline $\begin{array}{r}\text { Total } \\
\text { Cost } \\
(5000)\end{array}$ & current & ferred & $\begin{array}{r}\text { Total } \\
\text { Sovings }\end{array}$ \\
\hline 417 & 417 & & 0.13 \\
\hline 833 & 833 & 617 & 0.61 \\
\hline 1,250 & 1,250 & 833 & 0.82 \\
\hline 1,250 & 1.250 & 1,250 & 1.23 \\
\hline 1,250 & 1,250 & 1,250 & 1.64 \\
\hline 1,250 & 1,250 & 1,250 & 2.06 \\
\hline 1,250 & 1.250 & 1.250 & 2.47 \\
\hline 1.250 & 1.250 & 1.250 & 2.88 \\
\hline 0 & 0 & 1.250 & 2.80 \\
\hline 0 & 0 & 0 & 2.88 \\
\hline 0 & 0 & 0 & 2.88 \\
\hline 0 & 0 & 0 & 2.80 \\
\hline 0 & 0 & o & 2.80 \\
\hline 0 & 0 & 0 & 2.88 \\
\hline 0 & 0 & 0 & 2.80 \\
\hline 0 & 0 & o & 2.80 \\
\hline 0 & 0 & 0 & 2.88 \\
\hline 0 & 0 & 0 & 2.80 \\
\hline 0 & 0 & 0 & 2.88 \\
\hline 0 & 0 & 0 & 2.88 \\
\hline
\end{tabular}

$5,566 \quad 5,060$-.-vet Present value

506 -.-5000 Sevines

12,166 -.-Avg. man Servines

$4.2 \cdots-\cos$ 
Residential cooling Program--st. Thoms

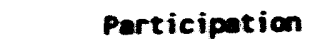

$x$ ven Total

Total inn Sovines

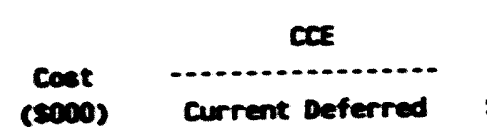

Total

ins

$\begin{array}{rrrrrr}1993 & 1 & 20 & 78 & 78 & 31 \\ 1994 & 2 & 40 & 156 & 234 & 94 \\ 1995 & 3 & 50 & 195 & 429 & 172 \\ 1996 & 4 & 50 & 195 & 625 & 250 \\ 1997 & 5 & 50 & 195 & 820 & 328 \\ 1996 & 6 & 50 & 195 & 1.015 & 406 \\ 1999 & 7 & 50 & 195 & 1,210 & 484 \\ 2000 & 8 & 50 & 195 & 1,405 & 562 \\ 2001 & 9 & 50 & 195 & 1.601 & 640 \\ 2002 & 10 & 50 & 195 & 1.796 & 718 \\ 2003 & 11 & 0 & 0 & 1,796 & 703 \\ 2004 & 12 & 0 & 0 & 1.796 & 671 \\ 2005 & 13 & 0 & 0 & 1,796 & 632 \\ 2006 & 14 & 0 & 0 & 1,796 & 593 \\ 2007 & 15 & 0 & 0 & 1.796 & 554 \\ 2000 & 16 & 0 & 0 & 1.796 & 515 \\ 2009 & 17 & 0 & 0 & 1.796 & 476 \\ 2010 & 18 & 0 & 0 & 1.796 & 437 \\ 2011 & 19 & 0 & 0 & 1.796 & 390 \\ 2012 & 20 & 0 & 0 & 1.796 & 359\end{array}$

$\begin{array}{rrrr}5 & 5 & & 0.01 \\ 10 & 10 & 5 & 0.03 \\ 12 & 12 & 10 & 0.15 \\ 12 & 12 & 12 & 0.07 \\ 12 & 12 & 12 & 0.09 \\ 12 & 12 & 12 & 0.12 \\ 12 & 12 & 12 & 0.16 \\ 12 & 12 & 12 & 0.16 \\ 12 & 12 & 12 & 0.18 \\ 12 & 12 & 12 & 0.21 \\ 0 & 0 & 12 & 0.20 \\ 0 & 0 & 0 & 0.19 \\ 0 & 0 & 0 & 0.18 \\ 0 & 0 & 0 & 0.17 \\ 0 & 0 & 0 & 0.16 \\ 0 & 0 & 0 & 0.15 \\ 0 & 0 & 0 & 0.16 \\ 0 & 0 & 0 & 0.12 \\ 0 & 0 & 0 & 0.11 \\ 0 & 0 & 0 & 0.10\end{array}$

Customer bese

390 (3,906*1/10 deprec. per year) cost/cust.

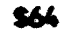

Serines/cust.

$400 \mathrm{kch}$

68

$$
\begin{aligned}
& 62 \text {-.-wet Present value } \\
& 6 \text { - - - seve sevines } \\
& 451 \text {-.-Ave. nth sevines } \\
& 1.4 \cdots--c 0 E
\end{aligned}
$$


Residential Cooling Prograr-st. Croix

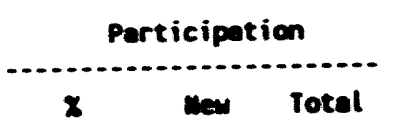

Total
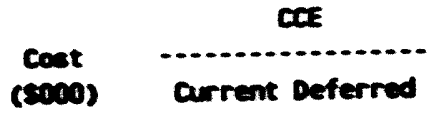
Total
ar

$x$ men Total

suines

Customer sese cost/cust.

Sevines/cust.

af

$\begin{array}{rr}73 & 73 \\ 165 & 218 \\ 181 & 399 \\ 181 & 580 \\ 181 & 762 \\ 181 & 963 \\ 181 & 1.126 \\ 181 & 1.306 \\ 181 & 1.487 \\ 181 & 1.668 \\ 0 & 1.668 \\ 0 & 1.668 \\ 0 & 1.668 \\ 0 & 1.668 \\ 0 & 1.668 \\ 0 & 1.668 \\ 0 & 1.668 \\ 0 & 1.668 \\ 0 & 1.668 \\ 0 & 1,668\end{array}$

29
87
160
232
305
377
450
522
595
667
653
624
508
551
515
479
442
486
370
336

363 (3,627-1/10 deprec. per vear) 364

$400 \mathrm{kth}$

0.6

$\begin{array}{cccc}5 & 5 & & 0.01 \\ 9 & 9 & 5 & 0.12 \\ 12 & 12 & 9 & 0.15 \\ 12 & 12 & 12 & 0.07 \\ 12 & 12 & 12 & 0.09 \\ 12 & 12 & 12 & 0.11 \\ 12 & 12 & 12 & 0.13 \\ 12 & 12 & 12 & 0.15 \\ 12 & 12 & 12 & 0.17 \\ 12 & 12 & 12 & 0.19 \\ 0 & 0 & 12 & 0.19 \\ 0 & 0 & 0 & 0.18 \\ 0 & 0 & 0 & 0.17 \\ 0 & 0 & 0 & 0.16 \\ 0 & 0 & 0 & 0.15 \\ 0 & 0 & 0 & 0.16 \\ 0 & 0 & 0 & 0.13 \\ 0 & 0 & 0 & 0.12 \\ 0 & 0 & 0 & 0.11 \\ 0 & 0 & 0 & 0.10 \\ & & 0 & \end{array}$

63

$$
\begin{aligned}
& 57 \text {-.-wet Present volue } \\
& 6 \text {-.-2000 Sevines } \\
& 419 \text {-.-Ave. mh Sevines } \\
& 1.4-\cdots-c c E
\end{aligned}
$$


A.2. RESIDENTIAL RETROFIT PROGRAM 
Residential Retrofit Program-St. Thames

\begin{tabular}{c} 
Participation \\
\hline$\times$ Mew Total
\end{tabular}

Total

sevinge

$\begin{array}{ll}1993 & 1 \\ 1994 & 2 \\ 1995 & 3 \\ 1996 & 4 \\ 1997 & 5 \\ 1998 & 6 \\ 1999 & 7 \\ 2000 & 8 \\ 2001 & 9 \\ 2002 & 10 \\ 2003 & 11 \\ 2004 & 12 \\ 2005 & 13 \\ 2006 & 14 \\ 2007 & 15 \\ 2008 & 16 \\ 2009 & 17 \\ 2010 & 18 \\ 2011 & 19 \\ 2012 & 20\end{array}$

Customer lase 19,522 Cost/cust.

Sevines/Cust.

5219
537

Total Muber of Customers

ah

0.6

af

Total
cost
(s000)
171
86
86
171
257
257
342
513
599
86
0
0
0
0
0
0
0
0
0
0

cer

arrent Deferred

17

$86 \quad 171 \quad 0.18$

$86 \quad 86 \quad 0.26$

$\begin{array}{lrr}17 & 86 & 0.36 \\ 257 & 171 & 0.54\end{array}$

$\begin{array}{lll}257 & 257 & 0.72\end{array}$

$\begin{array}{lll}342 & 257 & 0.96\end{array}$

$\begin{array}{lll}513 & 362 & 1.32\end{array}$

$599 \quad 513 \quad 1.74$

$86 \quad 599 \quad 1.80$

$\begin{array}{lll}0 & 86 & 1.74\end{array}$

- 0 1.7

$0 \quad 0 \quad 1.68$

001.62

$\begin{array}{lll}0 & 0 & 1.53 \\ 0 & 0 & 1.46\end{array}$

$\begin{array}{lll}0 & 0 & 1.32\end{array}$

001.14

$\begin{array}{lll}0 & 0 & 0.93\end{array}$
$1,413 \quad 1,204 \quad \cdots$-. Wet Present value

128 -.-2000 sevines

$3,842 \cdots$ - Awe wh sevines

$3.3--\cos (c / t a n)$ 
Residential Retrofit Program--st. Croix

Participation $x$ New Total

$\begin{array}{cc}1993 & 1 \\ 1994 & 2 \\ 1995 & 3 \\ 1996 & 4 \\ 1997 & 5 \\ 1998 & 6 \\ 1999 & 7 \\ 2000 & 8 \\ 2001 & 9 \\ 2002 & 10 \\ 2003 & 11 \\ 2004 & 12 \\ 2005 & 13 \\ 2006 & 14 \\ 2007 & 15 \\ 2008 & 16 \\ 2009 & 17 \\ 2010 & 18 \\ 2011 & 19 \\ 2012 & 20\end{array}$

\section{custoner Base} Cost/cust. Sevines/cust.

CLF

$\begin{array}{rr}725 & 725 \\ 363 & 1,008 \\ 363 & 1,451 \\ 725 & 2,176 \\ 1,088 & 3,265 \\ 1,008 & 4,353 \\ 1,451 & 5,804 \\ 2,176 & 7,900 \\ 2,539 & 10,519 \\ 363 & 10,802 \\ 0 & 0 \\ 0 & 0 \\ 0 & 0 \\ 0 & 0 \\ 0 & 0 \\ 0 & 0 \\ 0 & 0 \\ 0 & 0 \\ 0 & 0 \\ 0 & 0\end{array}$

390

584

79

1,169

1,753

2,337

3,117

4,285

5,649

5,844

5,649

5,552

5,454

5,260

4,967

4,675

4,206

3,701

3,020

2,922

18, 137 Total muber of customers $\$ 219$

537 Wh

0.4

\begin{tabular}{|c|c|c|c|}
\hline $\begin{array}{r}\text { Total } \\
\text { cost } \\
(5000)\end{array}$ & current D & & $\begin{array}{c}\text { Total } \\
\text { Sevines }\end{array}$ \\
\hline 159 & $\begin{array}{r}159 \\
79\end{array}$ & 159 & $\begin{array}{l}0.11 \\
0.17\end{array}$ \\
\hline 79 & 79 & 79 & 0.22 \\
\hline 159 & 159 & 79 & 0.33 \\
\hline 238 & 238 & 159 & 0.50 \\
\hline 238 & 238 & 238 & 0.67 \\
\hline 318 & 318 & 238 & 0.89 \\
\hline $4 \pi$ & $4 \pi$ & 318 & 1.22 \\
\hline 556 & 556 & $4 \pi$ & 1.61 \\
\hline 79 & 79 & 556 & 1.67 \\
\hline 0 & 0 & 79 & 1.61 \\
\hline 0 & 0 & 0 & 1.58 \\
\hline 0 & 0 & 0 & 1.56 \\
\hline 0 & 0 & 0 & 1.50 \\
\hline 0 & 0 & 0 & 1.42 \\
\hline 0 & 0 & 0 & 1.33 \\
\hline 0 & 0 & 0 & 1.22 \\
\hline 0 & 0 & 0 & 1.06 \\
\hline 0 & 0 & 0 & 0.86 \\
\hline 0 & 0 & $\begin{array}{l}0 \\
0\end{array}$ & 0.83 \\
\hline
\end{tabular}

$1,3131,193$-.-wet Present value

$$
\begin{aligned}
& 119 \text { - - - } 5000 \text { sevines } \\
& \text { 3,570 - - -Ave. men sevines }
\end{aligned}
$$$$
3.3 \text {-.-coe (c/lin) }
$$ 
A.3. COMMERCIAL/NDUSTRIAL TIME-OF-RETIREMENT PROGRAM 
Commercial-Industrial Air Conditioning Program--St. Thomas

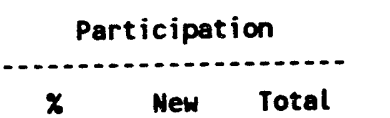

Total

Sovings

(\$000)

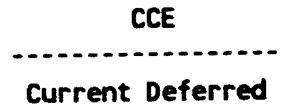

Total

Cavings

$\begin{array}{rr}1993 & 1 \\ 1994 & 2 \\ 1995 & 3 \\ 1996 & 4 \\ 1997 & 5 \\ 1998 & 6 \\ 1999 & 7 \\ 2000 & 8 \\ 2001 & 9 \\ 2002 & 10 \\ 2003 & 11 \\ 2004 & 12 \\ 2005 & 13 \\ 2006 & 14 \\ 2007 & 15 \\ 2008 & 16 \\ 2009 & 17 \\ 2010 & 18 \\ 2011 & 19 \\ 2012 & 20\end{array}$

97
195

97
195

97
292

49
146

292

$292 \quad 584$

$\begin{array}{lr}292 & 875 \\ 292 & 1,167\end{array}$

$292 \quad 1,167$

$292 \quad 1,459$

$\begin{array}{ll}292 & 1,751 \\ 292 & 2,042\end{array}$

$292 \quad 2,334$

$292 \quad 2,626$

$0 \quad 2,626$

0 2,626

2,626

2,626

2,626

2,626

2,626

2,626

2,626

2,626
2,626

438
584

584
729

875

1,021

1,167

1,313

1,289

1,240

1,167

, 094

1,021

948

875

802

729
656

34
68
103
103
103
103
103
103
103
103
0
0
0
0
0
0
0
0
0
0

$\begin{array}{lrl}\text { Customer Base } & 389 & (3,890 * 1 / 10 \text { per year }) \\ \text { Cost/Cust. } & \$ 352 & \\ \text { Savings/Cust. } & 500 & \mathrm{kth} \\ & & \\ \text { CLF } & 0.4 & \end{array}$

$\begin{array}{rrr}34 & & 0.01 \\ 68 & 34 & 0.04 \\ 103 & 68 & 0.08 \\ 103 & 103 & 0.12 \\ 103 & 103 & 0.17 \\ 103 & 103 & 0.21 \\ 103 & 103 & 0.25 \\ 103 & 103 & 0.29 \\ 103 & 103 & 0.33 \\ 103 & 103 & 0.37 \\ 0 & 103 & 0.37 \\ 0 & 0 & 0.35 \\ 0 & 0 & 0.33 \\ 0 & 0 & 0.31 \\ 0 & 0 & 0.29 \\ 0 & 0 & 0.27 \\ 0 & 0 & 0.25 \\ 0 & 0 & 0.23 \\ 0 & 0 & 0.21 \\ 0 & 0 & 0.19\end{array}$

540

$$
\begin{aligned}
& 491 \text {-.-Net Present Value } \\
& 49--5000 \text { Savings } \\
& 822 \text {-.-Avg. min Savings } \\
& 6.0 \text {-.-CCE (c/kth) }
\end{aligned}
$$




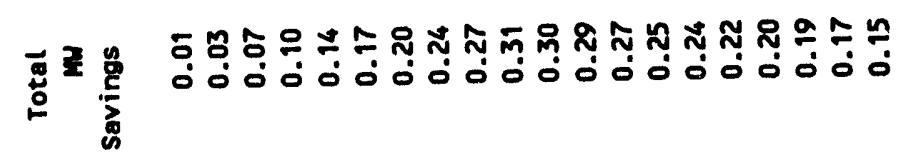

ళ

过

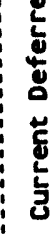

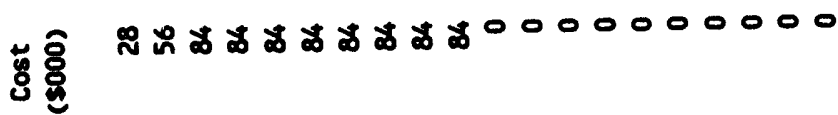

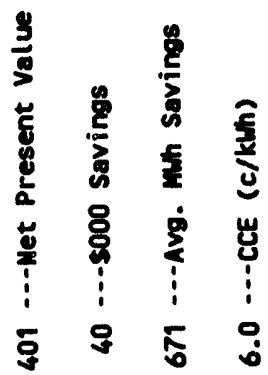

$\bar{y}$

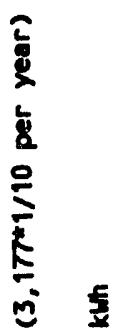

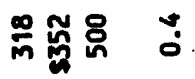

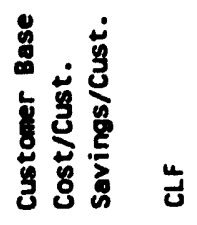


A.4. COMMERCIAL/NDUSTRIAL RETROFIT PROGRAM 
Commercial Lighting Program--st. Thomas

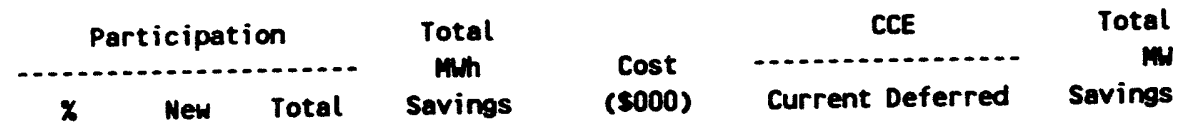

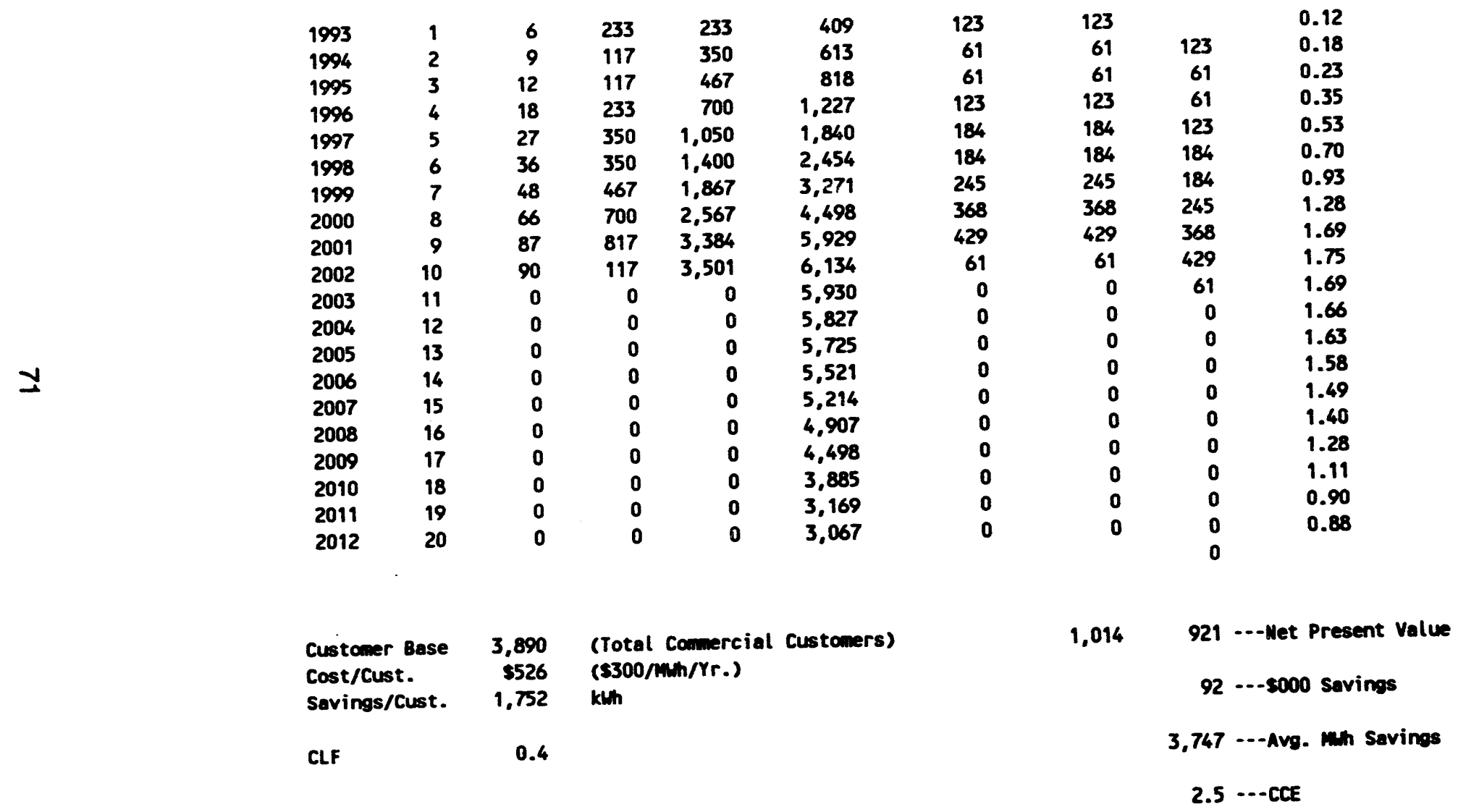




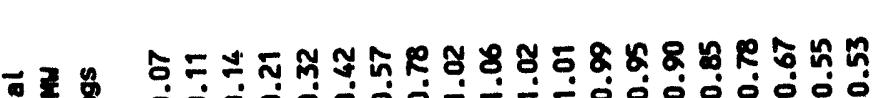

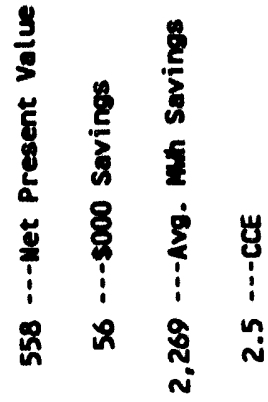

岁

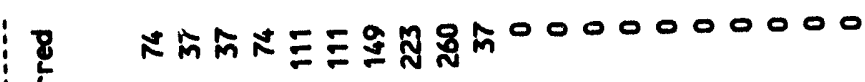

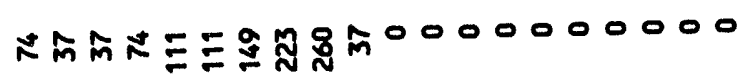

$\frac{1}{6}$

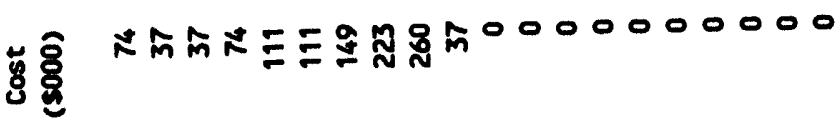

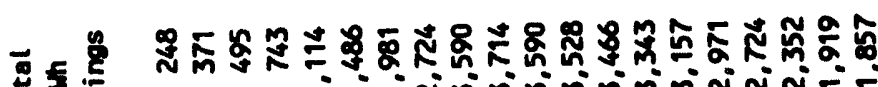

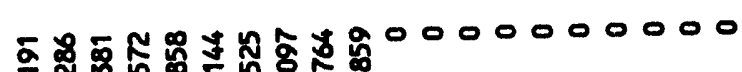
$\because \because N$ N

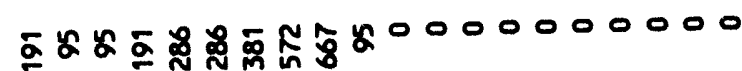

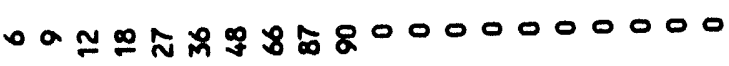

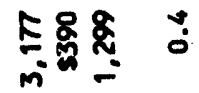

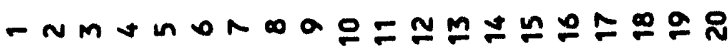

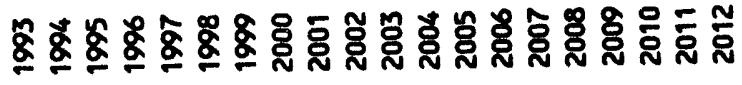

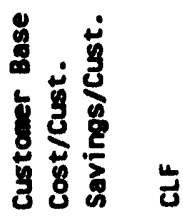




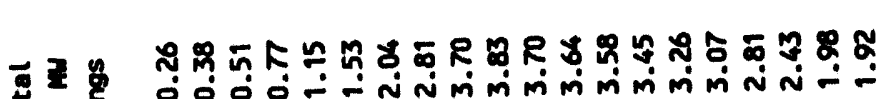
\& ठ

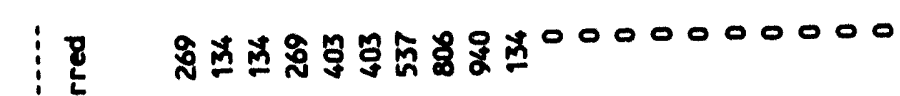
岁

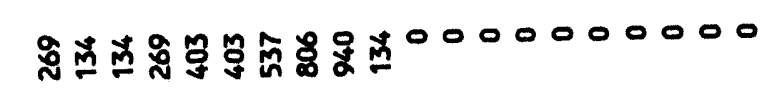

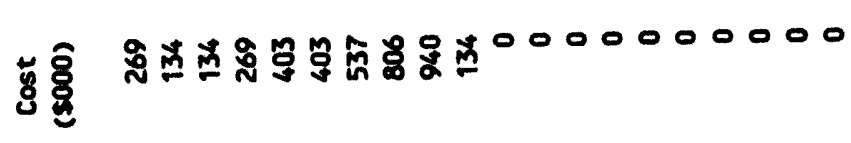

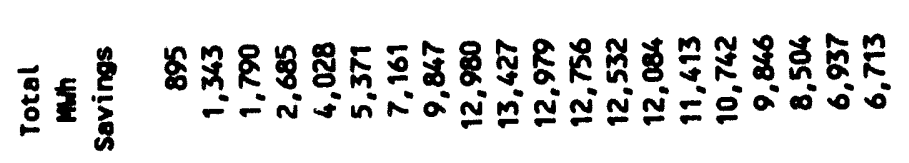

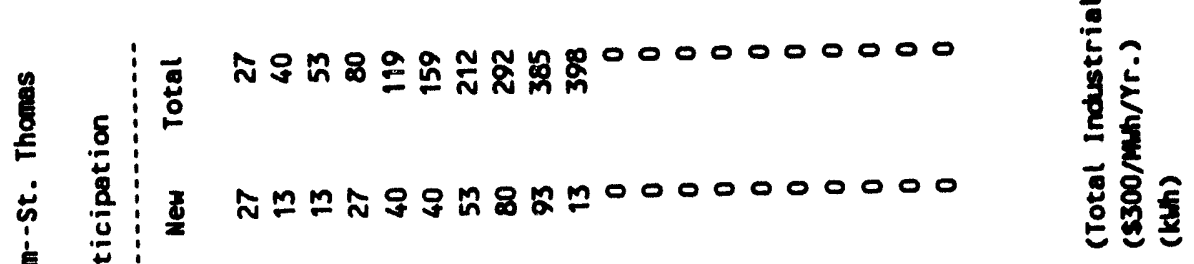

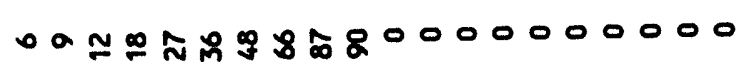

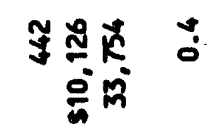

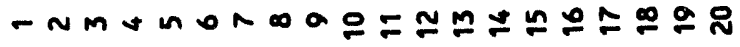

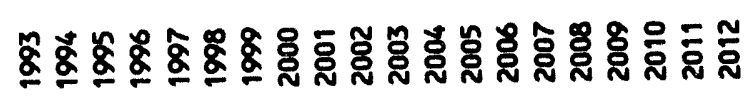

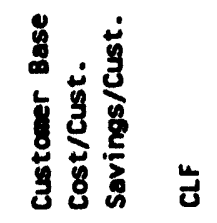


Inctustrial Lighting Program--St. Croix

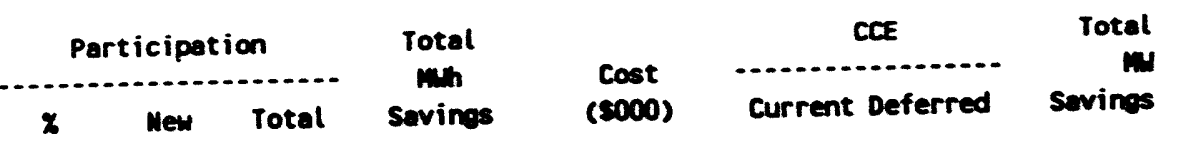

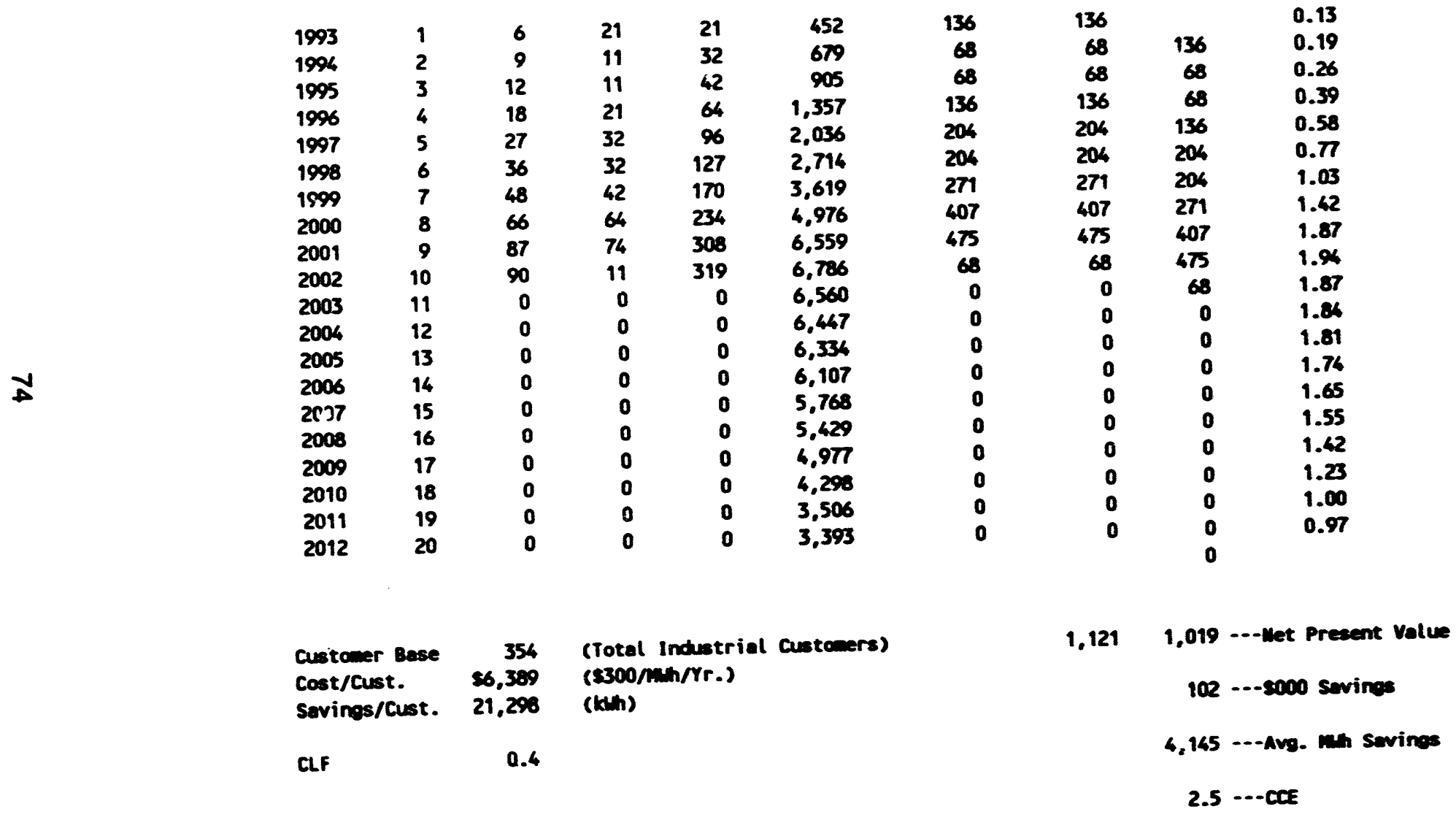


A.5. COMMERCIALINDUSTRIAL LOAD MANAGEMENT PROGRAM 
Load Kanogement Program-st. Thomas

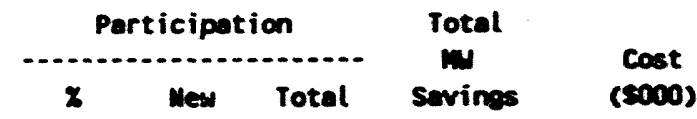

$\begin{array}{rrrrrrr}1993 & 1 & 2 & 78 & 78 & 0.39 & 39 \\ 1994 & 2 & 4 & 78 & 156 & 0.78 & 78 \\ 1995 & 3 & 7 & 117 & 272 & 1.36 & 136 \\ 1996 & 4 & 13 & 233 & 506 & 2.53 & 253 \\ 1997 & 5 & 21 & 311 & 817 & 4.06 & 408 \\ 1996 & 6 & 29 & 311 & 1,128 & 5.64 & 564 \\ 1999 & 7 & 37 & 311 & 1,439 & 7.20 & 720 \\ 2000 & 8 & 43 & 233 & 1,673 & 8.36 & 836 \\ 2001 & 9 & 47 & 156 & 1,828 & 9.14 & 914 \\ 2002 & 10 & 50 & 117 & 1,945 & 9.73 & 973 \\ 2003 & 11 & 0 & 0 & 1,965 & 9.73 & 973 \\ 2004 & 12 & 0 & 0 & 1,945 & 9.73 & 973 \\ 2005 & 13 & 0 & 0 & 1,945 & 9.73 & 973 \\ 2006 & 14 & 0 & 0 & 1,945 & 9.73 & 973 \\ 2007 & 15 & 0 & 0 & 1,945 & 9.73 & 973 \\ 2008 & 16 & 0 & 0 & 1,945 & 9.73 & 973 \\ 2009 & 17 & 0 & 0 & 1,945 & 9.73 & 973 \\ 2010 & 18 & 0 & 0 & 1,945 & 9.73 & 973 \\ 2011 & 19 & 0 & 0 & 1,945 & 9.73 & 973 \\ 2012 & 20 & 0 & 0 & 1,945 & 9.73 & 973\end{array}$

\footnotetext{
Customer base $3,890 \quad$ (Total Comercial Customers)

Cost/customer $\$ 500$ (\$500/ku/Yr.)

Sevines/Cust. 5 kW
} 
Loed Maneogeneric Progren--St. Thomes

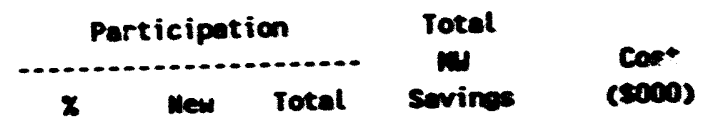

\begin{tabular}{|c|c|c|}
\hline $\begin{array}{l}64 \\
64\end{array}$ & 64 & $\begin{array}{l}0.32 \\
0.66\end{array}$ \\
\hline 95 & 2222 & 1.11 \\
\hline 191 & 613 & 2.07 \\
\hline 254 & 667 & 3.36 \\
\hline 256 & 921 & 4.61 \\
\hline 254 & 1,175 & 5.80 \\
\hline 191 & 1,366 & 6.83 \\
\hline 127 & 1,493 & 7.67 \\
\hline 95 & 1,509 & 7.96 \\
\hline 0 & 1,500 & 7.95 \\
\hline 0 & 1,509 & 7.95 \\
\hline 0 & 1,509 & 7.95 \\
\hline 0 & 1,529 & 7.95 \\
\hline 0 & 1,500 & 7.95 \\
\hline 0 & 1,500 & 7.55 \\
\hline 0 & 1,500 & 7.95 \\
\hline 0 & 1,500 & 7.95 \\
\hline 0 & 1,309 & 7.55 \\
\hline 0 & & \\
\hline
\end{tabular}

\section{antomer sace 3,17 (Total Comercial Cutcmars) costrantomer $\$ 500$ (\$500/tw/Tr.)}

sevines/ant. 5 
A.6. NEW CONSTRUCTION PROGRAM 
Residential wew Construction Progren--st. Thoms

\begin{tabular}{|c|c|c|c|c|c|c|c|c|c|c|c|}
\hline & & $\begin{array}{l}\text { Mote: } \\
\text { Total }\end{array}$ & $\begin{array}{l}\text { New } \\
\text { Momes }\end{array}$ & $\begin{array}{l}\mathrm{P} \\
\mathrm{x}^{\mathrm{P}}\end{array}$ & articipe & ion & $\begin{array}{l}\text { Total } \\
\text { Sonines }\end{array}$ & $\begin{array}{r}\text { Total } \\
\cos t \\
(5000)\end{array}$ & \multicolumn{2}{|c|}{$\begin{array}{c}\text { CCE } \\
\text { Current Deferred }\end{array}$} & $\begin{array}{r}\text { Total } \\
\text { Sovings }\end{array}$ \\
\hline 1993 & 1 & 19,815 & 146 & 25 & 37 & 37 & 78 & 50 & 50 & & 0.02 \\
\hline 1994 & 2 & 20,112 & 169 & so & 74 & 111 & 236 & 102 & 102 & so & 0.05 \\
\hline 1995 & 3 & 20,414 & 151 & 75 & 113 & 226 & $4 \pi$ & 155 & 155 & 102 & 0.11 \\
\hline 1996 & 4 & 20,720 & 153 & 75 & 115 & 339 & $\mathbf{2 1}$ & 157 & 157 & 155 & 0.16 \\
\hline 1997 & 5 & 21,031 & 155 & 75 & 117 & 455 & 969 & 159 & 159 & 157 & 0.22 \\
\hline 1998 & 6 & 21,366 & 158 & 75 & 118 & 576 & 1,221 & 162 & 162 & 159 & 0.20 \\
\hline 1999 & 7 & 21,666 & 160 & 75 & 120 & 694 & 1,676 & 164 & 166 & 162 & 0.36 \\
\hline 2000 & 8 & 21,991 & 162 & 75 & 122 & 816 & 1.736 & 167 & 167 & 164 & 0.60 \\
\hline 2001 & 9 & 22,321 & 165 & 75 & 126 & 939 & 1.999 & 169 & 169 & 167 & 0.66 \\
\hline 2002 & 10 & 22,656 & 167 & 75 & 126 & 1,065 & 2,266 & 172 & 172 & 169 & 0.52 \\
\hline 2003 & 11 & 22,996 & 170 & 75 & 127 & 1,192 & 2,537 & 176 & 176 & 172 & 0.58 \\
\hline 2004 & 12 & 23,361 & 172 & 75 & 129 & 1,322 & 2,812 & 177 & 177 & 176 & 0.66 \\
\hline 2005 & 13 & 23,691 & 175 & 75 & 131 & 1.653 & 3,092 & 180 & 180 & 177 & 0.71 \\
\hline 2006 & 14 & 26.066 & 178 & 75 & 133 & 1,586 & 3,375 & 182 & 182 & 180 & $0 . \pi$ \\
\hline 2007 & 15 & 24.407 & 180 & 75 & 135 & 1.721 & 3.663 & 185 & 185 & 182 & 0.84 \\
\hline 2008 & 16 & 24,773 & 183 & 75 & 137 & 1.659 & 3.955 & 180 & 188 & 185 & 0.90 \\
\hline 2009 & 17 & 25.145 & 186 & 75 & 139 & 1.990 & 4,252 & 191 & 191 & 188 & 0.97 \\
\hline 2010 & 18 & 25,522 & 189 & 75 & 161 & 2,139 & 4.553 & 193 & 193 & 191 & 1.06 \\
\hline 2011 & 19 & 25,905 & 191 & 75 & 164 & 2,203 & 4.858 & 196 & 196 & 193 & 1.11 \\
\hline 2012 & 20 & 26,293 & 196 & 75 & 166 & 2,629 & 5,168 & 199 & 199 & $\begin{array}{l}196 \\
199\end{array}$ & 1.18 \\
\hline $\begin{array}{l}\text { Custom } \\
\text { Cost/c } \\
\text { Sevine }\end{array}$ & ise & & $\begin{array}{r}\text { One-half } \\
51,368 \\
2,128\end{array}$ & $\begin{array}{l}\text { Mistorical } \\
\text { (kth) }\end{array}$ & Amint & irowth & & & 1,200 & $\begin{array}{r}1.166 \\
116\end{array}$ & $\begin{array}{l}\text {---wet Present Volue } \\
\text {-.--500 Sevines }\end{array}$ \\
\hline CLF & & & 0.5 & & & & & & & $\begin{array}{r}2,472 \\
4.7\end{array}$ & $\begin{array}{l}-- \text { Avg. mh Swines } \\
-\cdots-c c\end{array}$ \\
\hline
\end{tabular}


Residential Wew Construction Program-st. Croix

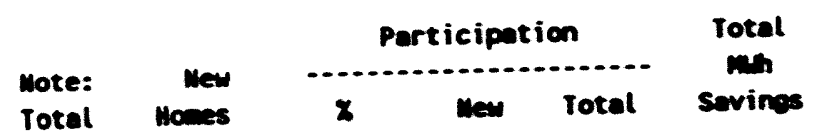

$\begin{array}{lll}1993 & 1 & 18,500 \\ 1994 & 2 & 18,870 \\ 1995 & 3 & 19,267 \\ 1996 & 4 & 19,632 \\ 1997 & 5 & 20,025 \\ 1998 & 6 & 20,425 \\ 1999 & 7 & 20,034 \\ 2000 & 8 & 21,250 \\ 2001 & 9 & 21,675 \\ 2002 & 10 & 22,109 \\ 2003 & 11 & 22,551 \\ 2004 & 12 & 23,002 \\ 2005 & 13 & 23,462 \\ 2006 & 16 & 23,931 \\ 2007 & 15 & 24,610 \\ 2000 & 16 & 26,098 \\ 2009 & 17 & 25,396 \\ 2010 & 18 & 25,904 \\ 2011 & 19 & 26,422 \\ 2012 & 20 & 26,951\end{array}$

\section{Customer Base} Cost/cust. Sevines/Cust.

CLF

$\begin{array}{lrrrr}181 & 25 & 45 & 45 & 96 \\ 185 & 50 & 92 & 138 & 293 \\ 189 & 75 & 142 & 279 & 596 \\ 192 & 75 & 146 & 426 & 901 \\ 196 & 75 & 147 & 571 & 1,215 \\ 200 & 75 & 150 & 721 & 1,536 \\ 204 & 75 & 153 & 876 & 1,860 \\ 208 & 75 & 156 & 1,030 & 2,193 \\ 213 & 75 & 159 & 1,190 & 2,532 \\ 217 & 75 & 163 & 1,352 & 2,876 \\ 221 & 75 & 166 & 1,518 & 3,231 \\ 226 & 75 & 169 & 1,687 & 3,591 \\ 230 & 75 & 173 & 1,860 & 3,958 \\ 235 & 75 & 176 & 2,036 & 4,332 \\ 239 & 75 & 179 & 2,215 & 6,714 \\ 264 & 75 & 183 & 2,390 & 5,106 \\ 249 & 75 & 187 & 2,505 & 5,501 \\ 256 & 75 & 190 & 2,776 & 5,907 \\ 259 & 75 & 194 & 2,970 & 6,320 \\ 264 & 75 & 196 & 3,168 & 6,742\end{array}$

One-half Mistorical Ammil Growth

51,368

2,128 (kn)

0.5

\begin{tabular}{|c|c|c|c|}
\hline $\begin{array}{r}\text { Total } \\
\text { cost } \\
(5000)\end{array}$ & current & red & $\begin{array}{r}\text { Total } \\
\text { Sevines }\end{array}$ \\
\hline 62 & 62 & & 0.02 \\
\hline 127 & 127 & 62 & 0.07 \\
\hline 196 & 196 & 127 & 0.16 \\
\hline 197 & 197 & 19 & 0.21 \\
\hline 201 & 201 & 197 & 0.28 \\
\hline 205 & 205 & 201 & 0.35 \\
\hline 210 & 210 & 205 & 0.42 \\
\hline 216 & 216 & 210 & 0.50 \\
\hline 218 & 218 & 214 & 0.58 \\
\hline 222 & 222 & 218 & 0.66 \\
\hline 227 & 227 & 222 & 0.76 \\
\hline 231 & 231 & 227 & 0.82 \\
\hline 236 & 236 & 231 & 0.90 \\
\hline 261 & 261 & 236 & 0.99 \\
\hline 246 & 266 & 261 & 1.08 \\
\hline 250 & 250 & 246 & 1.17 \\
\hline 255 & 255 & 250 & 1.26 \\
\hline 261 & 261 & 255 & 1.35 \\
\hline 266 & 266 & 261 & 1.46 \\
\hline 271 & $2 \pi$ & $\begin{array}{l}266 \\
271\end{array}$ & 1.56 \\
\hline
\end{tabular}

$1,647 \quad 1,497$-.-llet Present value

150 -.--5000 Serines

3,175 -.-Ave. an Servines

$4.7-.-\operatorname{ccc}$ 
INTERNAL DISTRIBUTION

$\begin{array}{llll}\text { 1. } & \text { K.R. Ballew } & 112 . & \text { C.H. Petrich } \\ 2 . & \text { D.J. Bjornstad } & 113 . & \text { R.M. Reed } \\ \text { 3. } & \text { E.L. Blaylock } & 114 . & \text { R.B. Shelton } \\ 4 . & \text { T.R. Curlee } & 115 . & \text { D.P. Vogt } \\ 5 . & \text { S. Damewood } & 116 . & \text { T.J. Wilbanks } \\ 6 . & \text { S.B. Floyd } & 117-119 . & \text { Lab Records } \\ 7 . & \text { S.W. Hadley } & 120 . & \text { Lab Records-RC } \\ 8-108 . & \text { L.J. Hill } & 121 . & \text { Patent Office } \\ 109 . & \text { E.L. Hillsman } & 122 . & \text { Document Ref. Sect. } \\ 110 . & \text { E. Hirst } & 123 . & \text { Cent. Res. Library } \\ 111 . & \text { R.D. Perlack } & & \end{array}$

\section{EXTERNAL DISTRIBUTION}

124-174. Ms. Claudette Young-Hinds, U.S. Virgin Islands Energy Office, 81 Castle Coakley Christiansted, St. Croix, U.S. Virgin Islands

175. Mr. Robert Chronowski, Alternative Energy Development, Inc., P.O. Box 7698, Silver Springs, MD 20907

176. Mr. Andrew Shapiro, Vermont Energy Investment Corp., 7 Lawson Lane, Burlington, VT 05401

177. Mr. Joe Eto, 1 Cyclotron Road, Building, Building 904000 , Berkeley, CA 94720

178. Mr. Mark Levine, 1 Cyclotron Road, building 90-4000, Berkeley, CA 94720

179. Ms. Beth Richards, Sandia Laboratories, Division 6223, P.O. Box 5800, Albuquerque, NM 87185

180. Mr. Andrew Krantz, Director, IRP Program, Office of Energy Efficiency and Renewable Energy, EE-141, Forrestal Bldg., 1000 Independence Ave., Washington, DC 20585

181. Mr. Skip Laitner, ACEEE, 1001 Connesticut Ave., NW, Suite 801, Washington, DC 20036

182. Paul Berkowitz, Director, DSM Analysis, Wisconsin Energy Conservation Corp., 3120 International Lane, Madison, WI 53704

183. George Edgar, Wisconsin Energy Conservation Corp., 3120 International Lane, Madison, WI 53704

184. Ronald Bowes, U.S. Department of Energy, EE-54, Forrestal Bldg., 1000 Independence Ave., Washington, DC 20585 


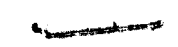

185. Asst. Manager, Energy Research and Development, DOEORO, P.O. BOX 2001, Oak Ridge, TN 38831-8600

186-187. OSTI, U.S. Department of Energy P.O. Box 62, Oak Ridge, TN 37831 



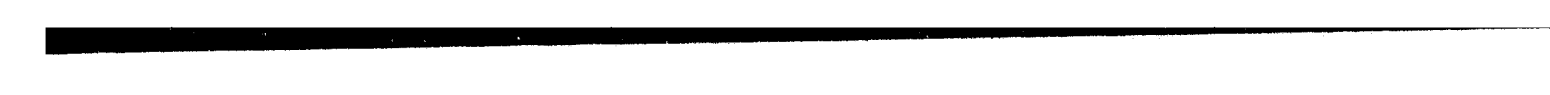

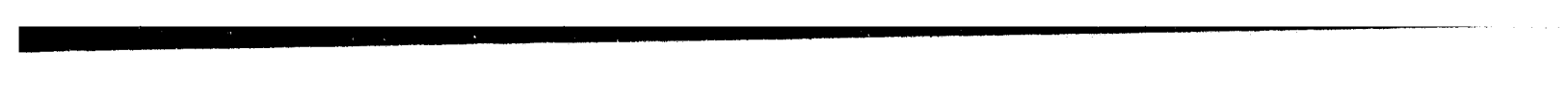

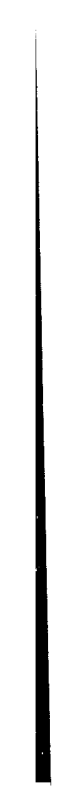

